NBER WORKING PAPER SERIES

\title{
EXPLORING THE ROLE OF LIMITED COMMITMENT CONSTRAINTS IN ARGENTINA'S "MISSING CAPITAL"
}

\author{
Marek Kapička \\ Finn Kydland \\ Carlos Zarazaga \\ Working Paper 26359 \\ http://www.nber.org/papers/w26359 \\ NATIONAL BUREAU OF ECONOMIC RESEARCH \\ 1050 Massachusetts Avenue \\ Cambridge, MA 02138 \\ December 2019, Revised January 2020
}

We are grateful to Manuel Amador, Federico Guerrero, Andrew Foerster, Grey Gordon, Sewon Hur, Fernando Leibovici, Rodolfo Manuelli, Andrés Neumeyer, Ignacio Presno, Erick Sager, Anna Sokolova, Mehmet Tosun, Mark Wynne, participants at the 2019 meeting of the Society for Economic Dynamics, at the 2019 Federal Reserve System Committee Meeting on International Economic Analysis at the Federal Reserve Bank of Cleveland, and seminar participants at the University of Nevada at Reno, for useful and constructive comments on an earlier version of this paper. The views expressed herein are those of the authors and do not necessarily reflect the views of the Federal Reserve Bank of Dallas, of the Federal Reserve System, or of the National Bureau of Economic Research.

NBER working papers are circulated for discussion and comment purposes. They have not been peer-reviewed or been subject to the review by the NBER Board of Directors that accompanies official NBER publications.

(C) 2019 by Marek Kapička, Finn Kydland, and Carlos Zarazaga. All rights reserved. Short sections of text, not to exceed two paragraphs, may be quoted without explicit permission provided that full credit, including $(\mathcal{)}$ notice, is given to the source. 
Exploring The Role of Limited Commitment Constraints in Argentina's "Missing Capital"

Marek Kapička, Finn Kydland, and Carlos Zarazaga

NBER Working Paper No. 26359

December 2019, Revised January 2020

JEL No. F34,F41,F42,F43,O19,O54

\section{ABSTRACT}

We study why capital accumulation in Argentina was slow in the 1990s and 2000s, despite high productivity growth and low international interest rates. We show that limited commitment constraints introduce two mechanisms. First, the response of investment to a total factor productivity increase is muted and short-lived, while the response to a decrease is large and persistent. Second, unlike in a first-best economy, low international interest rates may reduce capital accumulation, because they increase the relevance of future commitment constraints. A quantitative implementation of the model economy shows that the two mechanisms are quantitatively important for the dynamics of Argentina's capital accumulation. The model accounts for between $50 \%$ and $85 \%$ of the capital missing from Argentina in the two decades mentioned above, relative to what it would be in the absence of the limited commitment frictions.

Marek Kapička

CERGE-EI, a joint workplace of

Charles University and

the Economics Institute of

the Czech Academy of Sciences

Politických vězňů 7

11121 Prague

Czech Republic

mkapicka@gmail.com

Finn Kydland

Department of Economics

University of California, Santa Barbara

Santa Barbara, CA 93106-9210

and NBER

kydland@econ.ucsb.edu
Carlos Zarazaga

Federal Reserve Bank of Dallas

Research Department

2200 N. Pearl St

Dallas, TX 75201

USA

carlos.zarazaga@dal.frb.org 


\section{Introduction}

The relegation of Argentina from among the top ten nations in output per capita at the beginning of the 20th century to around 65th place a hundred years later has fascinated researchers and accordingly inspired innumerable studies. The relative decline is especially apparent during the so-called "lost decade" in the 1980s. Equally relevant for any attempt to account for Argentina's stagnation is the observation that in the subsequent decade, and the mid 2000s, total factor productivity (TFP) grew rapidly, yet the capital stock remained almost flat. Figure 1a documents the levels of the capital stock and of TFP in the period 1980-2008. The weakness of capital accumulation during periods of high productivity growth stands in contrast to the 1980s, when capital stock responded to low productivity growth by adjusting rapidly downwards. As a result, GDP growth was also relatively slow, as shown in Figure 1b.

The muted response of the capital stock in the mid 1990s and 2000s is even more puzzling when one takes into account that the then prevailing international real interest rates were low. International real interest rates, shown in Figure $2{ }^{1}{ }^{1}$ were about three percentage points lower in the mid-1990s than in the 1980s. Through the mid-2000s even lower rates failed to boost capital accumulation. Capital thus appears to be "missing" from Argentina's economy despite a favorable development of both productivity and international interest rates.

The goal of this paper is to investigate to what extent limited enforcement constraints can account for that "missing capital" puzzle, including the asymmetric response of that country's capital stock to productivity shocks and its apparent insensitivity to declines of the international interest rate. The conjecture that Argentina has faced limited enforcement constraints is plausible, given that Argentina defaulted on its external obligations at the beginning of the 1980s and that its capital stock was at a historical record high then. This may have convinced foreign investors that Argentina is inclined to repudiate foreign debt by strategic "opportunistic" considerations when capital and productivity are relatively high. As shown by Kehoe and Perri (2002) and others, governments will be particularly inclined to repudiate foreign debt precisely under those conditions.

Aware of the incentive to repudiate foreign debt, foreign investors will not fully exploit high returns to capital that they would take advantage of in the absence of en-

\footnotetext{
${ }^{1}$ The quarterly frequency counterpart of this series is similar to that reported by Neumeyer and Perri (2005), figure 5, for the period over which they overlap.
} 


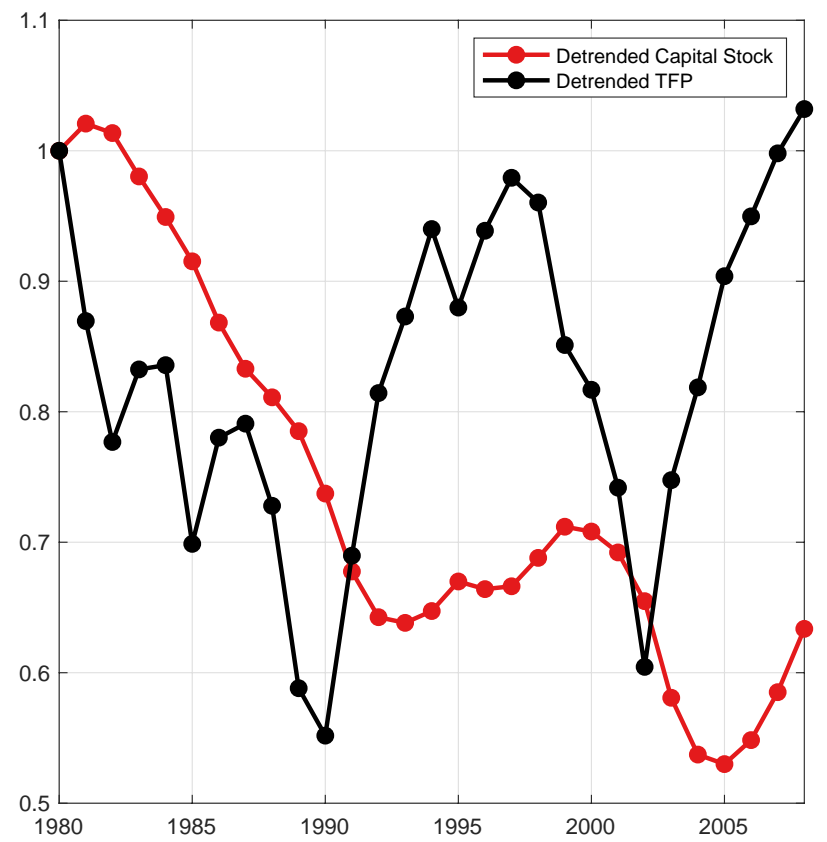

(a) Capital Stock and TFP. Index, 1980=100.

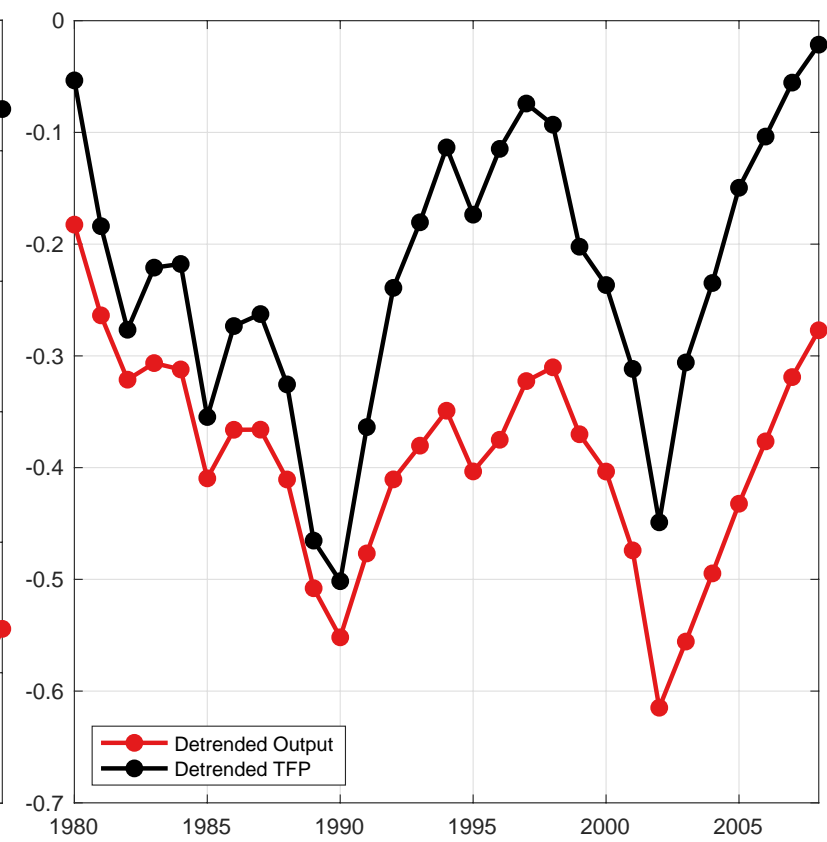

(b) GDP and TFP. Log index.

Figure 1: TFP, capital stock and GDP for Argentina, 1980-2008, detrended.

forcement problems. As a result the capital stock will not increase as much in times of high productivity. On the other hand, when productivity is low, the enforcement friction doesn't matter, because foreign investors have no interest in investing in a country offering a low return to capital which, precisely for that reason, falls. The capital stock thus responds asymmetrically to a productivity shock.

We show that the limited enforcement frictions can also account for the unresponsiveness of the capital stock to low international real interest rates. Specifically, we show that lower international interest rates can reduce, instead of increase, foreigners' incentives to invest in a small open economy whose rate of return on capital is particularly high after a sequence of high realizations of TFP. The economic intuition behind that mechanism is that the lower interest rates tend to make the limited enforcement constraints more severe, because they tend to shift consumption from the future to the present. As a result, consumption distortions associated with binding limited enforcement constraints are larger for lower international rates. This decreases the capital stock, because lower capital stock partially alleviates the limited enforcement constraints. This "second best" effect can even dominate the direct effect that lower international rates have on the required rate of return. We examine this mechanism in a simple special case that permits 


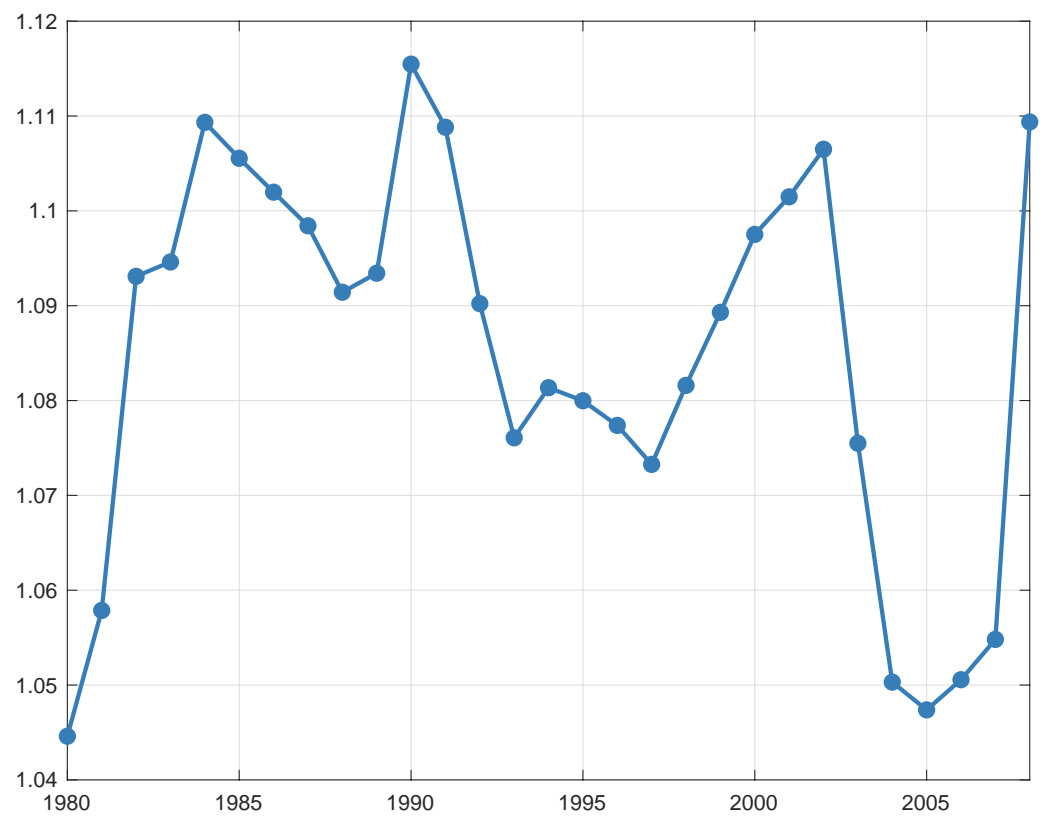

Figure 2: Gross international real interest rate: yields from Merrill Lynch's High Yield 175 U.S. Bond Index series and its successor, the Merrill Lynch's Low-Grade Corporate Bond series, minus expected inflation. Source: authors' calculations.

a closed-form solution and in a series of numerical examples.

Our quantitative exploration calibrates a deterministic growth model with enforcement frictions to Argentina's data. ${ }^{2}$ The key requirement for a successful quantitative exploration are reliable data about Argentina's capital stock. Since Argentina's capital stock is not regularly produced by the country's official statistical agencies, we extend the capital stock series constructed by Kydland and Zarazaga (2007) for the 1980-1997 period to the year 2008 with investment data by applying their same perpetual inventory method approach. For comparison, we use also the capital stock series from the PennWorld Tables 9.1. As discussed later, the differences between both series are substantial, but don't alter the fundamental message of the paper.

We find that the calibrated model traces the decline that that country's capital stock experienced during the 1980s with remarkable accuracy because, as predicted by the theory, the limited commitment constraints were almost never binding during that decade. At the same time, the limited enforcement frictions were often binding in the subsequent two decades, accounting therefore for between $50 \%$ and $85 \%$ of the capital stock

\footnotetext{
${ }^{2}$ Kehoe and Perri (2004) and Aguiar and Amador (2011) also use a deterministic perfect foresight environment.
} 
missing from the Argentine economy, when compared with that which would have been observed in a small open economy not afflicted by such a limited commitment friction. The model is successful also in replicating Argentina's capital stock asymmetric response to positive and negative changes of its total factor productivity and to its seemingly subdued reaction to lower international interest rates. The relatively good quantitative performance of the model is especially noteworthy given that the paper stays away from introducing exogenous costs of default to improve the matching between the model predictions and the data, as most of the existing literature does.

To check the quantitative implications of the limited commitment constraints, the paper performs numerical experiments that assume that those constraints disappear, first after 1991 and then after 2002. The capital stock predicted by these exercises turns out to be, on average, about $40 \%$ higher between 1991 and 2008 than in the model with the constraints. This result implies that workers would have enjoyed 13\% higher real wages on average if Argentina did not have enforcement problems. That same calibration implies that, in steady state, real wages would be permanently higher by about that same percentage in a small open economy with commitment than without it.

The remaining sections of the paper are structured as follows. Section 2 overviews the related literature. Section 3 presents the small open economy environment. Section 4 characterizes the constrained efficient allocation implied by the optimal contract between the small open economy and the risk-neutral foreign lender. ${ }^{3}$ Section 5 investigates the mechanisms that generate the asymmetric responses of the capital stock to changes in productivity and its insensitivity to the international real interest rates. Section 6 provides details of the data sources, construction of the capital stock series, calibrates the model economy to Argentina's data and studies the role of both asymmetries. Section 7 elaborates on the benefits to Argentina of getting rid of the limited commitment friction. Section 8 studies the sensitivity of the results to an alternative calibration of the model economy. Section 9 offers concluding remarks.

\section{Related Literature}

The quantitative implementation of the model economy to Argentina was motivated by Kydland and Zarazaga (2007), who investigated, in the context of a closed economy,

\footnotetext{
${ }^{3}$ Decentralization of the efficient allocation can be found in Appendix A.
} 
the role that total factor productivity, taken as an exogenous stochastic process, had in that country's secular stagnation. They were the first to point out that Argentina might suffer from a "missing capital puzzle," which they largely traced to their finding that that country's capital stock also exhibited an asymmetric response of its capital stock to negative and positive productivity shocks in the 1980-1997 period they studied. They conjectured that the puzzle could be better established, and eventually resolved, in a small open economy uncommitted to honor its external debt obligations, except under the threat of permanent exclusion from international financial markets.

The model economy of this paper is related to the literature that studies allocations that are constrained by the fact that at least some contractual debt obligations cannot be enforced, and economic agents have no incentives to honor them, except for the threat of exclusion from credit markets. Thomas and Worrall (1994) were among the first to demonstrate formally that limited commitment constraints have a negative impact on foreign direct investment. Marcet and Marimon (1992) analyze the implications of those frictions in a stochastic growth model and show, numerically, that enforcement constraints substantially impair capital accumulation, investment, and economic growth. Similar results for firm dynamics are obtained by Albuquerque and Hopenhayn (2004). Kehoe and Perri (2002) study the quantitative implications of those constraints when present in both countries of a two-country model, but their focus is on the features that the commitment friction induces in the resulting international business cycle statistics. Kehoe and Perri (2004) examine that model economy under the same perfect foresight assumption adopted in this paper, with the purpose of characterizing the constrained efficient allocation emerging from the optimal contract between the two limited commitment economies. Aguiar and Amador (2011) study the consequences along several dimensions of introducing limited commitment constraints in a small open economy. Like us, they appeal to a deterministic framework in order to examine the role of political frictions in slowing the economy's convergence to the steady state of a small open economy where such frictions die down in the long run.

None of the papers cited above allow the small open economy to discount future payoffs at a weakly higher rate than the international interest rate. There is, however, a fairly long list of papers that, like this one, contemplate the possibility that the small open economy, uncommitted to honor its outstanding debt obligations, discounts the future at a rate permitted also to be higher than the international real interest rate. They include those by Aguiar et al. (2009), Tsyrennikov (2013), Dovis (2018), and Restrepo- 
Echavarria (2019). These papers can be divided, in turn, into those whose contributions are more theoretical in nature and those who examine the model predictions with the data along different dimensions.

That by Dovis (2018) falls in the first category, providing a rich set of theoretical implications by adding a private information friction to a small open economy with limited commitment constraints, but in the context of an open economy without capital. The empirical implications of a similar environment is examined by Tsyrennikov (2013), but his conclusion, that limited commitment constraints are not quantitatively important when moral hazard is also present, may be biased by the assumption that investment fully depreciates in one period. It should be noted that, following standard practice and in contrast with this paper, his introduces exogenous costs of default in the model.

In line with findings of this paper, a more favorable assessment of the empirical relevance of limited commitment constraints emerges from those papers with an empirical orientation that do include capital in the analysis. That is the case of the model economy studied by Aguiar et al. (2009) who show that, in combination with a small open economy's government discount factor lower than the international interest rate, the limited commitment friction accounts for the "debt overhang" effect, that is, for the fact that in many emerging market economies, a higher government debt comes hand-in-hand with lower investment levels.

Restrepo-Echavarria (2019) offers an even more positive view of the role of limited commitment constraints in accounting for important aspects of the evidence for Latin American economies. Her model economy is a stochastic version of the one in this paper, except for the presence of endogenous labor input and the absence of adjustment costs to investment. Ignoring the adjustment costs is justifiable given her focus on replicating the observed consumption patterns, but is important for matching capital stock patterns. The success of her model along the consumption dimension complements that of this paper along the capital stock dimension. The substantial differences in the values of parameters that both papers calibrate to Argentina's data, especially the depreciation rate, are not inconsequential for the results, however, and therefore deserve further scrutiny.

Also related to this paper is that of Neumeyer and Perri (2005), who investigate the role of international real interest rates and default risk in emerging market economies. In addition to substantial modelling differences, they also don't address the question of why capital accumulation was weak in Argentina in the mid 1990's, when the inter- 
national real interest rates had substantially come down from the peaks reached in the prior decade.

Finally, it is worth mentioning that limited commitment constraints are included also in the analyses of Gordon and Guerron-Quintana (2018) and Rebelo et al. (2018), although the environment in which their small open economies operate is rather removed from the one in this paper. In particular, their small open economy's external debt obligations don't emerge from the solution to an optimal contract with a foreign lender. Rather, they are determined by that economy's optimal portfolio decisions, which exploits to that end the availability of securities offering insurance against different risks at actuarially fair prices. Both papers, in contrast with this one, include exogenous costs of defaults and assume that the small open economy is not permanently excluded from international credit markets after failing to honor foreign debt contractual obligations. Although both papers use data from Argentina to calibrate some parameter values, that country's evidence is not otherwise relevant for the questions they address.

\section{Environment}

The economy is deterministic. It consists of a risk neutral international lender and of a small open economy whose population of identical working age individuals, of size $N_{t}$ in period $t$, grows exogenously at rate $\eta, N_{t}=(1+\eta)^{t} N_{0}$. The representative household standing in for all of them consumes $C_{t} \geq 0$ in period $t$ and evaluates sequences of consumption according to

$$
V\left(\left\{C_{t}\right\}\right)=\sum_{t=0}^{\infty} \beta^{t} N_{t} U\left(\frac{C_{t}}{N_{t}}\right)
$$

where $0<\beta<1$ is the discount factor. We assume that the utility function $U$ exhibits a constant relative risk aversion:

$$
U(C)=\frac{C^{1-\sigma}}{1-\sigma^{\prime}}
$$

where $\sigma>0$ is the coefficient of relative risk aversion. The aggregate production function of the country is

$$
F\left(A_{t}, K_{t}, N_{t}\right)=A_{t} K_{t}^{\theta} N_{t}^{1-\theta}
$$


where $K_{t} \geq 0$ is the beginning-of-period $t$ capital stock, $A_{t}>0$ is total factor productivity in period $t$, and $\theta \in[0,1]$ is the capital share. The total factor productivity sequence is exogenous. We assume that after some sufficiently distant period $T$, it grows at rate $\zeta$.

The law of motion for capital is

$$
K_{t+1}=(1-\delta) K_{t}+I_{t}
$$

where $I_{t}$ is investment and $\delta$ is the depreciation rate. The initial capital stock $K_{0}$ is given.

As is standard in open economy models, capital stock adjustments are costly. We assume that the adjustment costs are given by $\Phi\left(K_{t}, K_{t+1}\right)$. The function $\Phi$ is quadratic in the growth rate of the capital stock, and proportional to the current capital stock:

$$
\Phi\left(K_{t}, K_{t+1}\right)=\frac{\kappa}{2}\left(\frac{K_{t+1}-\omega K_{t}}{\omega K_{t}}\right)^{2} K_{t} .
$$

where the parameter $\kappa$ measures the strength of the adjustment costs. The function $\Phi$ reaches a minimum of zero for capital growth $K_{t+1} / K_{t}=\omega$. We will later set it so that, along the balanced growth path, the adjustment costs are equal to zero. Given this normalization, the adjustment cost will modify the model dynamics, but will have the same balanced growth path as a model without adjustment costs.

The country can borrow from (or save with) the international lender. The lender is risk neutral and fully commits to the contract. That includes the commitment not to renegotiate in case the borrower deviates from the contract. The lender discounts cash flows between periods $t-1$ and $t$ by an international interest rate $R_{t}^{*} \geq 0$. The sequence of international interest rates $\left\{R_{t+1}^{*}\right\}$ is exogenous. It can be time varying, but is constant after a sufficiently distant period $T$ at a level $R^{*}$.

Balanced Growth. The properties of the utility, production, and adjustment cost functions imply that the economy has a balanced growth, where all variables grow at a constant rate. Output, consumption and capital stock grow at rate $(1+\eta)(1+\gamma)$, where $1+\gamma=(1+\zeta)^{\frac{1}{1-\theta}}$ is the growth of per capita values. We detrend the variables by setting

$$
a_{t}=\frac{A_{t}}{(1+\zeta)^{t}}, \quad k_{t}=\frac{K_{t}}{(1+\eta)^{t}(1+\gamma)^{t}}, \quad c_{t}=\frac{C_{t}}{(1+\eta)^{t}(1+\gamma)^{t}}, \quad i_{t}=\frac{I_{t}}{(1+\eta)^{t}(1+\gamma)^{t}} .
$$


Since $A$ grows at rate $\zeta$ after period T, the normalized TFP sequence $\left\{a_{t}\right\}$ is bounded and is equal to some constant $a$ after period $T$. After the normalization, the representative agent's utility function is now written as

$$
v\left(\left\{c_{t}\right\}\right)=\sum_{t=0}^{\infty} \hat{\beta}^{t} U\left(c_{t}\right)
$$

where the discount factor is modified by $\hat{\beta}=\beta(1+\eta)(1+\gamma)^{1-\sigma}$. The law of motion for capital is now

$$
(1+\eta)(1+\gamma) k_{t+1}=(1-\delta) k_{t}+i_{t} .
$$

We also set the adjustment cost parameter $\omega=(1+\gamma)(1+\eta)$ to make sure that, along the balanced growth path, where $k_{t}$ is constant, the adjustment costs are zero. For clarity of the presentation, we will use a general notation for the the adjustment cost function $\phi\left(k_{t}, k_{t+1}\right)=\frac{\kappa}{2}\left(k_{t+1}-k_{t}\right)^{2} / k_{t}$, as well as for the production function $f\left(a_{t}, k_{t}\right)=a_{t} k_{t}^{\theta}$ wherever possible.

We make two assumptions about the long-run international interest rates:

\section{Assumption 1.}

$$
(1+\eta)(1+\gamma)<R^{*} \leq \frac{(1+\gamma)^{\sigma}}{\beta}
$$

The first inequality implies that the present value of any bounded sequence of resources is finite. This assumption is our equivalent of what is called "high implied interest rates" in the general equilibrium versions of the limited commitment models (Kehoe and Perri (2004)), and is imposed in order to ensure that the efficient allocations can be decentralized as a competitive equilibrium. The second assumption means that the borrower is weakly more impatient than the lender. ${ }^{4}$ It can be justified for example by political economy frictions in the domestic country, as in Aguiar et al. (2009) or Aguiar and Amador (2011), something that is likely to be relevant for a country like Argentina.

\footnotetext{
${ }^{4}$ As one can deduce from the assumption, we call both parties equally patient in the growth economy if the modified discount factor of the lender $(1+\eta)(1+\gamma) / R_{t}^{*}$ equals to the modified discount factor of the borrower, $\beta(1+\eta)(1+\gamma)^{1-\sigma}$.
} 


\section{Constrained Efficient Allocations}

We first consider the constrained efficient allocations for this economy. At time zero, the country and the lender sign a contract that specifies sequences of transfers from the borrower to the lender, $\left\{t_{t}\right\}$, consumption $\left\{c_{t}\right\}$ and capital stock $\left\{k_{t+1}\right\}$. The transfers can be positive or negative. The resource constraint for the economy is

$$
c_{t}+(1+\eta)(1+\gamma) k_{t+1}=f\left(a_{t}, k_{t}\right)+(1-\delta) k_{t}-\phi\left(k_{t}, k_{t+1}\right)-t r_{t}
$$

We require that the lender gets a present value of transfers of at least $b_{0}$. Define the implied discount factor between period 0 and $t$ to be $Q_{t}^{*}=\prod_{j=1}^{t} 1 / R_{j}^{*}$, with $Q_{0}^{*}=1$. Then the requirement is

$$
\sum_{t=0}^{\infty} Q_{t}^{*}(1+\eta)^{t}(1+\gamma)^{t} t r_{t} \geq b_{0}
$$

The present value of transfers $b_{0}$ is a parameter of the contract. As usual, by varying the value of $b_{0}$, we can trace out the whole Pareto frontier for the problem.

The country faces a commitment problem. At any time, it can renege on the contract, and refuse to repay its debt. If that happens, the contract is terminated, and the country moves to autarky. Autarky is permanent, and the country will never again have a chance to sign a new contract, although it can accumulate capital on its own. The lender, on the other hand, has no commitment problems and always fulfills its contract obligations. The value of autarky in period $t$ is given by

$$
v_{t}^{\text {aut }}\left(k_{t}\right)=\max _{\left\{c_{t+j}, k_{t+1+j}\right\}} \sum_{j=0}^{\infty} \hat{\beta}^{j} U\left(c_{t+j}\right) .
$$

subject to the nonnegativity constraints $c_{t} \geq 0, k_{t+1} \geq 0$, and the closed economy resource constraints

$$
c_{t+j}=f\left(a_{t+j}, k_{t+j}\right)+(1-\delta) k_{t+j}-\phi\left(k_{t+j}, k_{t+j+1}\right)-(1+\eta)(1+\gamma) k_{t+j+1} .
$$

Without loss of generality, the contract requires that, in any period, the value of the 
contract cannot be smaller than the value of being in autarky:

$$
\sum_{j=0}^{\infty} \hat{\beta}^{j} U\left(c_{t+j}\right) \geq v_{t}^{\text {aut }}\left(k_{t}\right), \quad \forall t \geq 0
$$

Definition 1. Given exogenous sequences $\left\{a_{t}, R_{t}^{*}\right\}$, lender's profits $b_{0}$ and initial capital $k_{0}$, the optimal contract consists of feasible sequences $\left\{c_{t}, k_{t+1}, t r_{t}\right\}$ that maximize the country's lifetime utility (1) subject to the resource constraint (5), promise-keeping constraint for the lender (6) and the limited commitment constraint (7).

We define the relative discount factor of the lender, relative to that of the borrower, to be

$$
p_{t}=\frac{Q_{t}^{*}(1+\gamma)^{\sigma t}}{\beta^{t}} \text {. }
$$

Assumption 1 implies that $p_{t}$ is ultimately weakly increasing over time, reflecting the fact that, as time goes on, the difference between lender's and borrower's discounts grows. Let $\lambda>0$ be the Lagrange multiplier on the promise-keeping constraint and $\beta^{t} \mu_{t} \geq 0$ be the Lagrange multiplier on the limited commitment constraint in period $t$. The first-order condition with respect to consumption is

$$
U^{\prime}\left(c_{t}\right)\left(1+\sum_{s=0}^{t} \mu_{s}\right)=\lambda p_{t}
$$

The optimal consumption sequence has standard properties of economies with limited commitment. An increase in consumption in period $t$ not only increases the agents' utility directly, but also relaxes all limited commitment constraints up to period $t$. It is, however, costly for the lender, and tightens the promise keeping constraint (6), with period- $t$ cost $\lambda p_{t}$. Evaluating the first-order condition (8) at two consecutive periods yields the following intertemporal condition that must hold in the optimum:

$$
U^{\prime}\left(c_{t}\right)=\frac{\beta R_{t+1}^{*}}{(1+\gamma)^{\sigma}} \frac{1+\sum_{s=0}^{t+1} \mu_{s}}{1+\sum_{s=0}^{t} \mu_{s}} U^{\prime}\left(c_{t+1}\right)
$$

If the limited commitment constraint (7) does not bind, the marginal utility of consumption increases at rate $(1+\gamma)^{\sigma} /\left(\beta R_{t+1}^{*}\right)-1$, and consumption correspondingly decreases. If the limited commitment constraint binds, $\mu_{t}>0$ and consumption permanently increases, in order to prevent the country from reneging on the contract. 
The optimal capital stock is characterized by two conditions. One is the first-order condition in capital,

$$
R_{t+1}^{*}\left(1+\phi_{2, t}\right)=f_{k, t+1}+1-\delta-\phi_{1, t+1}-\frac{\mu_{t+1}}{\lambda p_{t+1}} \frac{d v_{t+1}^{\text {aut }}\left(k_{t+1}\right)}{d k_{t+1}}
$$

where the derivatives of the adjustment cost function are

$$
\begin{aligned}
& \phi_{1, t}=\phi_{1}\left(k_{t}, k_{t+1}\right)=-\kappa \frac{k_{t+1}-k_{t}}{k_{t}}-\frac{\kappa}{2}\left(\frac{k_{t+1}-k_{t}}{k_{t}}\right)^{2}, \\
& \phi_{2, t}=\phi_{2}\left(k_{t}, k_{t+1}\right)=\frac{\kappa}{(1+\eta)(1+\gamma)} \frac{k_{t+1}-k_{t}}{k_{t}} .
\end{aligned}
$$

Equation (10) shows that an increase in the capital stock in period $t$ has an additional negative effect in that it raises the value of autarky in the next period, and so tightens the limited commitment constraint. This decreases the optimal capital stock and current investment. $^{5}$ The adjustment costs have three effects on the optimal level of capital costs. The first two are standard: along the transition path where the capital stock is growing, the future marginal benefit of investment is increased by $-\phi_{1}>0$, because a higher investment today will decrease the adjustment cost incurred tomorrow. The future marginal benefit is discounted by $1 / R_{t+1}^{*}$. On the other hand, the marginal cost of investment today increases by $\phi_{2}>0$, because the current adjustment cost increases. Depending on the size of both effects, the investment will decrease or increase. In a limited commitment economy, there is an additional third effect on the value of capital in autarky. By differentiation of the value function in autarky, we obtain

$$
\frac{d v_{t}^{\text {aut }}\left(k_{t}\right)}{d k_{t}}=U^{\prime}\left(g_{t}^{\text {aut }}\left(k_{t}\right)\right)\left(f_{k, t}+1-\delta-\phi_{1, t}^{\text {aut }}\right)
$$

where $g_{t}^{\text {aut }}\left(k_{t}\right)$ is the optimal consumption policy in autarky, and $\phi^{\text {aut }}$ are the resulting adjustment costs. Note that $\phi_{1, t}^{\text {aut }}$ will in general be different from $\phi_{1, t}$, because capital stock in autarky follows a different path than along the contract.

\footnotetext{
${ }^{5}$ In a two-country model of Kehoe and Perri (2004), there is an additional effect that works in the opposite direction: binding limited commitment constraints increase future consumption and, given limited resources, encourage current investment. This effect is absent in our model, where the lender has unlimited resources.
} 
The second optimality condition for capital is the transversality condition

$$
\lim _{t \rightarrow \infty}\left[\frac{(1+\gamma)(1+\eta)}{R^{*}}\right]^{t} k_{t+1}=0
$$

The first-order conditions in consumption and capital stock (8) and (10), the complementary slackness conditions, the transversality conditon (11), and the constraints (5), (6) and (7) completely characterize the optimal allocations.

The Euler Equation. Combining the equations above to eliminate the rate of return $R_{t+1}^{*}$ yields the following expression for the Euler equation:

$$
\frac{U^{\prime}\left(c_{t}\right)}{\beta(1+\gamma)^{-\sigma} U^{\prime}\left(c_{t+1}\right)}\left(1+\phi_{2, t}\right)=\left(1-\Delta_{t+1}\right)\left(f_{k, t+1}+1-\delta-\phi_{1, t+1}\right),
$$

where the intertemporal wedge $\Delta_{t+1}$ is given by

$$
\Delta_{t+1}=\frac{\mu_{t+1}}{1+\sum_{s=0}^{t} \mu_{s}}\left(\frac{U^{\prime}\left(c_{t+1}^{\text {aut }}\right)}{U^{\prime}\left(c_{t+1}\right)} \frac{f_{k, t+1}+1-\delta-\phi_{1, t+1}^{\text {aut }}}{f_{k, t+1}+1-\delta-\phi_{1, t+1}}-1\right)
$$

If the limited commitment constraint does not bind tomorrow, then $\Delta=0$ and the Euler equation reduces to its standard frictionless form. If the limited commitment constraint binds tomorrow, then the wedge $\Delta$ will in general be nonzero. There are, however, two opposing forces on the intertemporal wedge, and so the wedge can be positive or negative. A positive force behind the intertemporal wedge is due to the fact that higher capital stock makes the value of autarky more attractive. This makes a higher capital stock less valuable. A negative force behind the intertemporal wedge comes from fact that the binding limited commitment constraint increases consumption tomorrow and increases the left-hand side of (12), which is the inverse of the marginal rate of intertemporal substitution.

If the adjustment costs are zero, then the bracketed term in the expression for the intertemporal wedge reduces to $U^{\prime}\left(c_{t+1}^{\text {aut }}\right) / U^{\prime}\left(c_{t+1}\right)-1$, and its sign depends only on the relative consumption in autarky and in the contract. If consumption in the autarky falls below consumption in the contract, then the value of capital in autarky is relatively high, the first effect dominates, and the intertemporal wedge is positive. Otherwise, the 
intertemporal wedge is negative.

\subsection{Steady State}

What happens when the economy converges to the steady state? We will now show that the result depends critically on whether the borrower is strictly more impatient than lender or not in the long run. If both are equally patient, then the economy converges to a first-best limit, while if the borrower is strictly more impatient, it converges to the steady state of a closed economy.

Proposition 1. Suppose that the adjustment costs are zero. If $\beta R^{*}=(1+\gamma)^{\sigma}$ then $k_{t}$ converges to the first best steady state level of capital. If $\beta R^{*}<(1+\gamma)^{\sigma}$ then $k_{t}$ and $c_{t}$ converge to their closed economy steady state levels.

Proof. First note that the dynamics of consumption and capital in autarky is the same as in a closed economy. The steady state level of capital in autarky $k_{s s}^{\text {aut }}$ satisfies

$$
f_{k}\left(k_{s s}^{\text {aut }}\right)+1-\delta=(1+\gamma)^{\sigma} / \beta
$$

Consumption in autarky after period $T$ is given by the optimal policy function $g^{\text {aut }}(k)$ which solves a standard dynamic programming problem of optimal growth and is strictly increasing. In particular, consumption immediately after defaulting in steady state is $c_{1}^{\text {aut }}=g^{\text {aut }}\left(k_{s s}\right)$, while consumption in the steady state of the autarky is $c_{s s}^{\text {aut }}=$ $g^{\text {aut }}\left(k_{s s}^{\text {aut }}\right)$. In between, $c_{\tau}^{\text {aut }}=\left(g^{\text {aut }}\right)^{\tau}\left(k_{s s}\right)$, where $\tau$ denotes the number of periods spent in autarky. The consumption sequence in autarky $\left\{c_{\tau}^{\text {aut }}\right\}$ is between $c_{1}^{\text {aut }}$ and its limit $c_{s s}^{\text {aut }}$, to which it monotonically converges.

To simplify notation, let $\psi=(1+\gamma)^{\sigma} /\left(\beta R^{*}\right) \geq 1$. In the steady state, consumption and capital are constant at $c_{s s}$ and $k_{s s}$ and the first-order conditions (9) and (10) converge to

$$
\begin{aligned}
\psi & =\lim _{t \rightarrow \infty} \frac{1+\sum_{s=0}^{t+1} \mu_{s}}{1+\sum_{s=0}^{t} \mu_{s}} \\
R^{*} & =\left[f_{k}\left(k_{s s}\right)+1-\delta\right]\left[1-\rho \frac{U^{\prime}\left(g^{\text {aut }}\left(k_{s s}\right)\right)}{\lambda}\right],
\end{aligned}
$$

where $\rho$ is the steady state value of the ratio $\mu_{t+1} / p_{t+1}$. 
Consider first the case when $\psi=1$. Then equation (14) implies that $\mu_{t+1}$ must converge to zero. Hence $\rho=0$ and the marginal product of capital satisfies $f_{k}\left(k_{s s}\right)+1-$ $\delta=R^{*}$, which is its first-best level.

Consider now the case when $\psi>1$. Write $\mu_{t}=\rho \psi^{t}$. Solving for $\psi$ from (14) and using (8) yields

$$
\rho=\frac{\psi-1}{\psi} \frac{\lambda}{U^{\prime}\left(c_{s s}\right)}>0
$$

That is, the limited commitment constraint must bind in the steady state. As a result, the steady state transfer to the lender $t r_{s s}$ cannot be strictly negative. If it were, the continuation present value of lender's profits is strictly negative and the lender is better off by mimicking autarky in steady state, which delivers zero profits and leaves the lifetime utility of the borrower unchanged. The steady state transfer to the lender $t_{s s}$ cannot be strictly positive either. If it were, moving to autarky increases the borrower's resources in every future period and must yield strictly higher lifetime utility than the optimal contract, violating the limited commitment constraint (7). Hence, $t r_{s s}$ must be zero. The optimal steady state consumption is given by the resource constraint (5),

$$
c_{s s}=f\left(a, k_{s s}\right)-(\delta+\eta+\gamma+\eta \gamma) k_{s s} .
$$

It is obvious that the steady state level of capital must be below its golden rule level, otherwise one can increase the borrower's consumption and utility by reducing the capital stock and saving resources.

We will now show that $k_{s s}=k_{s s}^{\text {aut }}$. Suppose, by contradiction, that $k_{s s}>k_{s s}^{\text {aut }}$. Then

$$
c_{s s}=f\left(a, k_{s s}\right)-(\delta+\eta+\gamma+\eta \gamma) k_{s s}>f\left(a, k_{s s}^{\text {aut }}\right)-(\delta+\eta+\gamma+\eta \gamma) k_{s s}^{\text {aut }}=c_{s s}^{\text {aut }},
$$

where the first equality follows from (16), the inequality from the fact that $k_{s s}$ is below its golden rule level and the proposition that is to be contradicted, and the last equality follows from the steady state of the closed economy. Substitute now $\rho$ out of equation (15) and rewrite it as

$$
\frac{(1+\gamma)^{\sigma}}{\beta}=\left[f_{k}\left(k_{s s}\right)+1-\delta\right]\left[\psi+(1-\psi) \frac{U^{\prime}\left(g^{\text {aut }}\left(k_{s s}\right)\right)}{U^{\prime}\left(c_{s s}\right)}\right] .
$$


For (17) to hold simultaneously with (13), it must be that

$$
c_{s s}>g^{\text {aut }}\left(k_{s s}\right)=c_{1}^{\text {aut }} .
$$

Since the consumption sequence in autarky monotonically converges from $c_{1}^{\text {aut }}$ to $c_{s s}^{\text {aut }}$, it must satisfy $c_{s s}>c_{\tau}^{\text {aut }}$ for all $\tau \geq 0$. But then the limited commitment constraint (7) must be slack, a contradiction. An analogous argument rules out $k_{s s}<k_{s s}^{\text {aut }}$ by showing that the limited commitment constraint must then be violated. ${ }^{6}$ Hence, it must be that $k_{s S}=k_{s s}^{\text {aut }}$. It then follows from the resource constraint that $c_{s s}=c_{s s}^{\text {aut }}$.

Proposition 1 shows that, as long as the borrowers are relatively more impatient than lenders, the first-best and the second-best economy have different implications in the long run. While the capital stock in the first-best economy remains at its first-best level, capital stock in the second-best economy converges to the closed economy level. Moreover, borrowing constraints prevent consumption from falling, and so consumption settles at a closed economy level in the long run as well. As a result, the steady state will be independent of the international risk free rate $R^{*}$. Lower international interest rates may have a transitory effect on the capital stock, but will have no effect on it in the long run. Proposition 1 also implies optimal capital and consumption sequences are both bounded, and so is the transfer sequence.

Proposition 1 is also useful for calibration of the model. If the target steady state capital-output ratio is smaller than the one implied by the first best economy, given by $\theta /\left(R^{*}+\delta-1\right)$, then the borrowers must be more impatient than the lender, and the steady state of the economy can be calibrated as if the economy were closed, independently of the risk-free rate $R^{*}$.

\subsection{Decentralizing the Efficient Allocations}

The Pareto efficient allocations can be decentralized as a self-enforcing equilibrium where individuals in the country borrow and lend directly from abroad using one-period bonds, the government appropriately chooses capital income tax rates (to satisfy the Euler equation (9) and so induce the optimal capital stock), collects debt payments from

\footnotetext{
${ }^{6}$ The assumption of zero adjustment costs is useful in this step, because the adjustment costs reduce the value of autarky, but not the value of the contract, where the capital stock is constant.
} 
the agents to pass them to foreigners, and makes default decisions on the collected debt (so as to make sure that the limited commitment constraint (7) holds). The self-enforcing equilibrium is itself an outcome of a sustainable equilibrium, in the language of Chari and Kehoe (1990) and Kehoe and Perri (2004), where the government chooses its policies optimally for any given history of past policies, consumers take policies as given, and the government chooses policies consistent with autarky for off-equilibrium histories. While the decentralization is obviously necessary to justify our focus on the constrained efficient allocations, it is relatively standard, and is relegated to an online Appendix A.

\section{Inspecting the mechanism}

To understand the workings of the model, and the forces that determine capital accumulation as well as the dynamics of consumption, we now consider several simple numerical examples. Unless stated otherwise, all examples assume that the utility is logarithmic, capital share $\theta$ is one third, there is full depreciation $(\delta=1)$, there is no population and TFP growth, and the discount factor $\beta$ equals 0.96 . We fist assume that there are no adjustment costs and that $\beta R_{t}^{*}=1$ in all periods. ${ }^{7}$ We focus on two aspects: how capital stock responds to a positive versus negative productivity shock, and how it responds to a change in the interest rate.

\subsection{Response to a productivity shock.}

Consider an anticipated one-time increase in the total factor productivity $a$. The total factor productivity increases in period 5 and then reverts back to its original level, as in Panel 3a. Panel 3b shows how the capital stock responds in a closed economy, in an economy with commitment, and in an economy with limited commitment. In the firstbest and the second-best economy, capital and consumption decisions are separated, because the economy can borrow and save. In both economies, capital stock is at its steady state level in all periods except in period 5. In both the first-best and the secondbest economy, capital stock increases when the marginal product of capital is high. The increase in capital stock thus happens one period earlier than in a closed economy,

\footnotetext{
${ }^{7}$ We solve the model by solving the corresponding first-order conditions (8) and (10). We iterate on the set of binding limited commitment constraints by dropping the ones that are slack and by adding those that are violated, until convergence. We then iterate on the Lagrange multiplier $\lambda$ until the model yields the required initial debt $d_{0}$.
} 


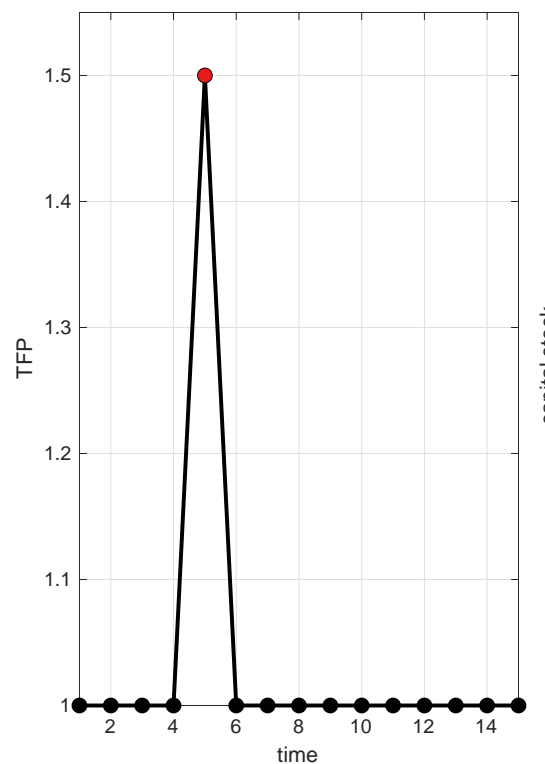

(a) Total Factor Productivity

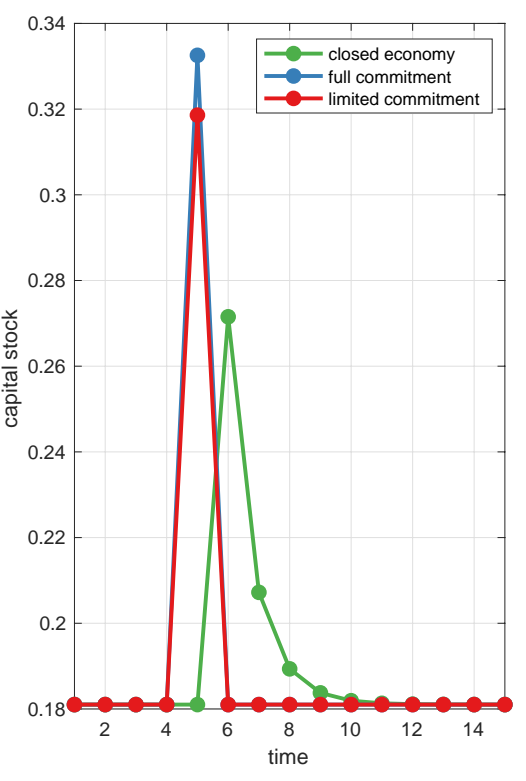

(b) Capital Stock

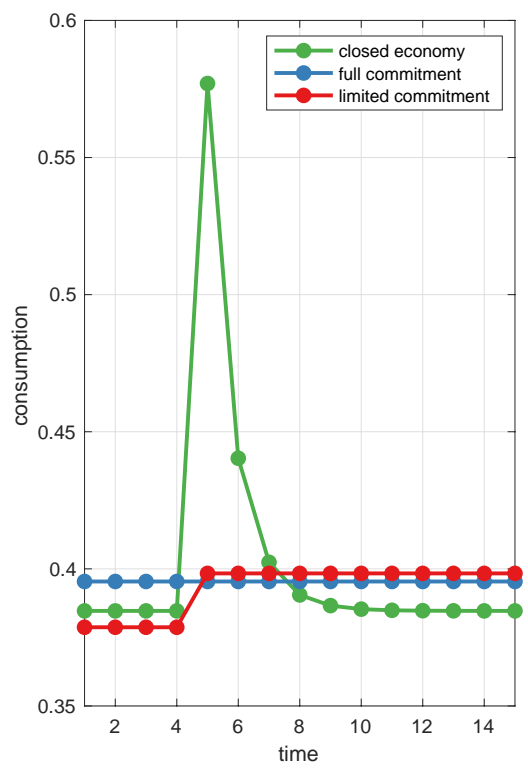

(c) Consumption

Figure 3: Response to a temporary positive TFP shock without adjustment costs. Red dots in panel (a) denote periods when the limited commitment constraint binds.

because the mechanism behind the increase in capital stock is different: In a closed economy, the desire to smooth consumption prevents the agents to increase capital stock in period 5, because that would require high investment in period 4 , and a drop in consumption. Instead, investment only happens in period 5 when the economy has more resources, and the effect on capital stock is purely transitory.

In the second best economy, the desire to invest in capital stock is reduced by the limited commitment constraint considerations. As panel 3a shows, the limited commitment constraint binds in period 5. That is, the first-best level of capital stock would prompt the agents to default and move to autarky. This reduces the capital stock in period 5. The level of consumption, shown in panel $3 \mathrm{c}$ is, however, pushed upward. This stands in contrast to the closed economy, where consumption decreases after the shock.

Figure 4 shows a response to a one-time decrease in the productivity shock in period 5. The response of the second-best economy is now different in two aspects. First, since the limited commitment constraint does not bind at the time of the negative productivity shock, capital stock decreases by the same amount as in the first-best economy. Second, the limiting commitment constraint now binds in all the periods following the decrease in productivity. To see why, note that the agents consume more than their production in period 5. Thus, they need to transfer resources back to the lender after period 5. 


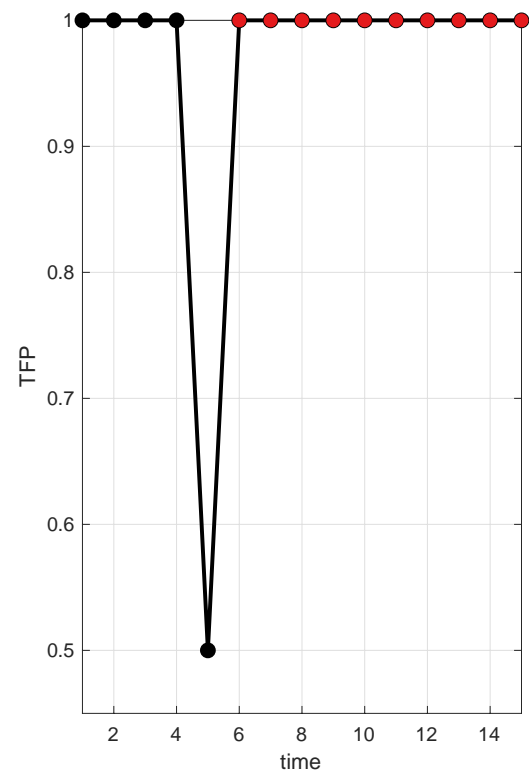

(a) Total Factor Productivity

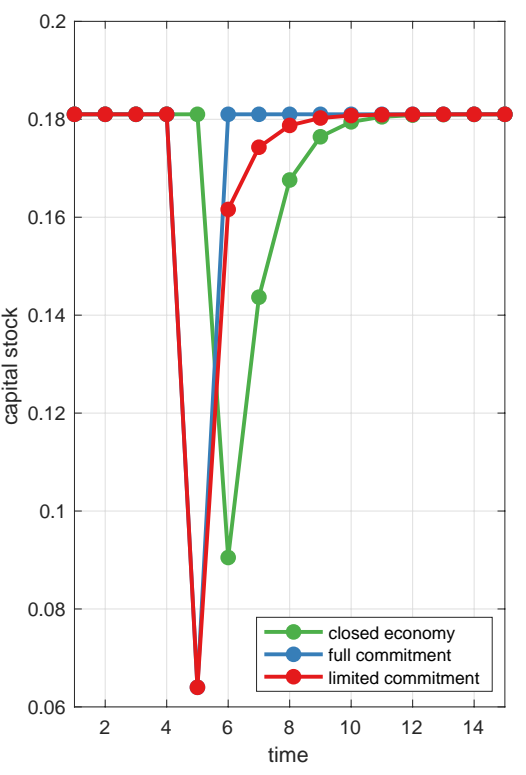

(b) Capital Stock

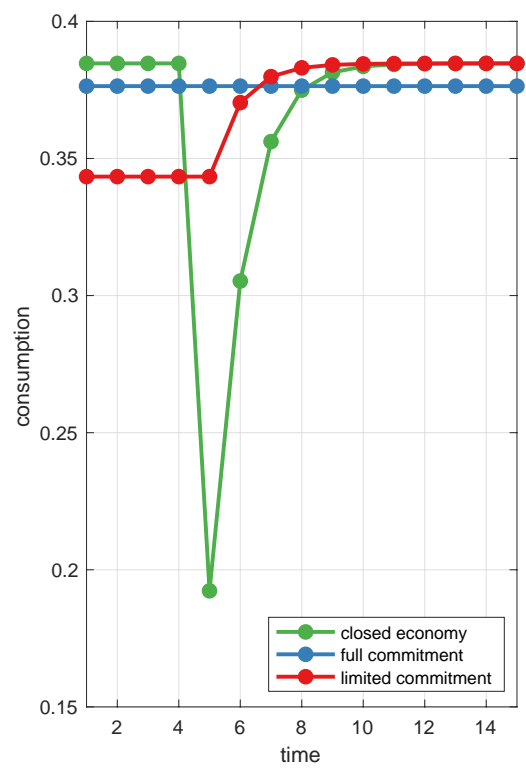

(c) Consumption

Figure 4: Response to a temporary negative TFP shock without adjustment costs. Red dots in Figure 1 denote periods when the limited commitment constraint binds.

There are no future shocks, and so no benefit from future insurance. If the capital stock immediately reverted back to the first-best level, they would prefer to default. To prevent them from defaulting, the value of autarky needs to be decreased by decreasing the capital stock. The recovery of the capital stock is now sluggish compared to the first-best economy, although the decline in period 5 is identical.

Overall, figures 3 and 4 show that the limited commitment constraints introduced an asymmetry to the capital accumulation process. The response to a positive shock is muted, and the reversal to the steady state level is rapid, while a response to a negative shock is large, and the reversal to the steady state level is slow.

When the adjustment costs are introduced, the dynamics of the capital stocks differs in certain aspects: the build-up of the capital stock is gradual in all three economies, and starts before the productivity shock happens. Similarly, the return to the steady state level of the capital stock is slower. But the asymmetric response of the capital stock in the second best economy to a positive and negative productivity shock is still there, and the mechanism is identical to the one explained above. 


\subsection{The role of international interest rates.}

Previous examples were simulated under the assumption that $\beta R_{t}^{*}=1$, and so the required rate of return on capital investment exactly offsets the discount rate. What happens if the investors require a lower rate of return?

An example solved. To understand how the international interest rates interact with capital accumulation, we first consider an example where $\sigma=0$ and so the period utility is linear. As in Aguiar and Amador (2011), a case with linear utility has a simple closed form dynamics. To simplify the problem further, we continue assuming that there are no adjustment costs, and that $\gamma=\eta=0$. For simplicity, we consider a case when the nonnegativity constraint on consumption is not binding.

The first-order condition for consumption (8) now simplifies to $\mu_{0}=\lambda-1$, and

$$
\frac{\mu_{t}}{p_{t}}=\left(1-\beta R_{t}^{*}\right) \lambda, \quad t \geq 1 .
$$

The Lagrange multiplier $\mu_{t}$ is always strictly positive if the lender is more patient and $\beta R_{t}^{*}<1$, and is zero only if both parties are equally patient. Moreover, $\mu_{t}$ always moves in the opposite direction than the international interest rate. That is, the limited commitment problems become more severe if the world interest rate decreases (in a sense that the normalized Lagrange multiplier $\mu_{t} / p_{t}$ increases). This has important consequences for the dynamics of investment and capital stock. The first-order condition (10) now becomes

$$
R_{t+1}^{*}=\left(f_{k, t+1}+1-\delta\right)\left(1-\frac{\mu_{t+1}}{\lambda p_{t+1}}\right)=\left(f_{k, t+1}+1-\delta\right)\left[1-\left(1-\beta R_{t+1}^{*}\right)\right]
$$

The first term in the last bracket represents a direct effect of the international interest rates on the marginal product of capital: lower international interest rates decrease the required marginal product of capital, and increase the capital stock. This is a standard "first-best" result. The second term in the last bracket represents the effect of the limited commitment constraints on the capital stock. Rearranging the expression (18) yields

$$
f_{k, t+1}=\delta-1+\frac{1}{\beta} \text {. }
$$

The international interest rate $R_{t+1}^{*}$ has cancelled out, and the marginal product of capital 
equals $\delta-1+1 / \beta$, a steady state closed economy level. In this case, the positive direct effect of lower international interest rates is exactly offset by a negative effect of the limited commitment constraints. The second best capital stock is independent of the international interest rate, not only in the steady state, but in every period except period zero.

Numerical examples with concave utility. To investigate how robust the results from the linear utility case are, we now consider numerical examples for various degrees of risk aversion.

Figure 5 shows the capital stock response to a one-time increase in productivity in period 5 for various values of the international rate of return $R_{t}^{*}$, and for $\sigma=0.5,1$ and 5. In this numerical example, the limited commitment constraint always binds in period 5. In other periods shown in figure 5, the limited commitment constraint does not bind, and the capital stock is at its first best level. Panel 5b shows the capital stock in period 5, which is the period when productivity increases. In the first-best economy, the response of capital stock to the increase in the interest rate is unambiguous. Foreign investors require a higher rate of return, which decreases the capital stock.

In the second-best economy, the optimal capital stock reacts very differently. Lower interest rates lead to a decrease, rather than increase, of the capital stock. Compared to the linear utility case, the indirect effects of the limited commitment constraints are strengthened. To understand why this is the case, specialize the optimality condition (10) for zero adjustment costs to obtain an alternative equation for the optimal capital stock:

$$
R_{t+1}^{*}=\left(f_{k, t+1}+1-\delta\right)\left[1-\frac{\mu_{t+1}}{1+\sum_{s=0}^{t+1} \mu_{s}} \frac{U^{\prime}\left(g_{t+1}^{\mathrm{aut}}\left(k_{t+1}\right)\right)}{U^{\prime}\left(c_{t+1}\right)}\right] .
$$

Relative to the linear utility case, the wedge between the return to capital $f_{k, t+1}+1-\delta$ and the international rate $R_{t+1}^{*}$ is given not only by the severity of the limited commitment constraints, but also by the difference between the marginal utility of consumption in autarky and on the contract. The new term typically weakens the importance of limited commitment: The limited commitment constraints usually bind in good states, and in good states the consumption in autarky $g_{t}^{\text {aut }}\left(k_{t}\right)$ tends to exceed the consumption on the contract. The marginal value of capital in autarky is thus diminished. However, this term turns out to be relatively unimportant in the numerical exercises we have 


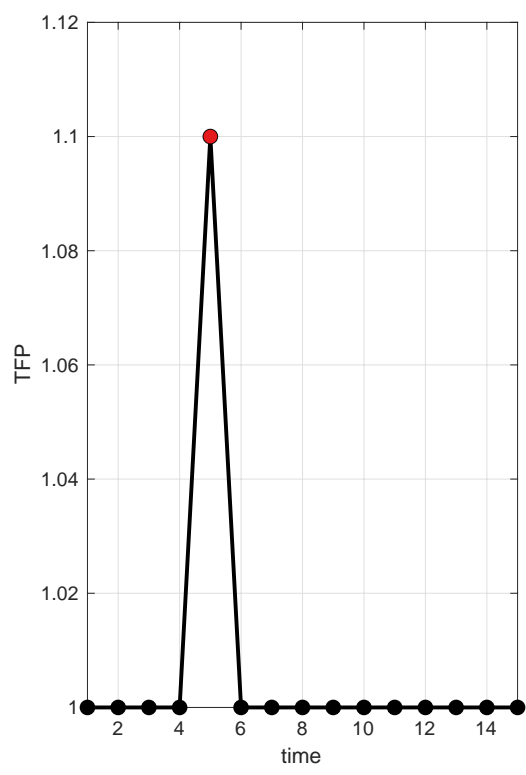

(a) Total Factor Productivity

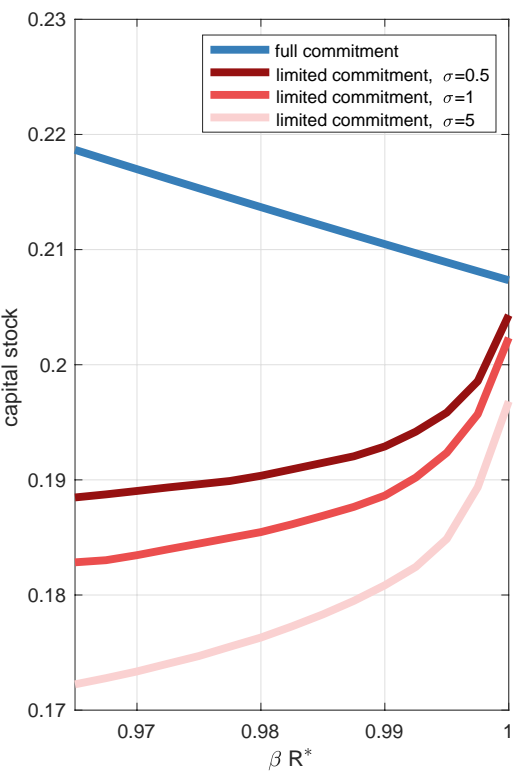

(b) Capital Stock in period 5

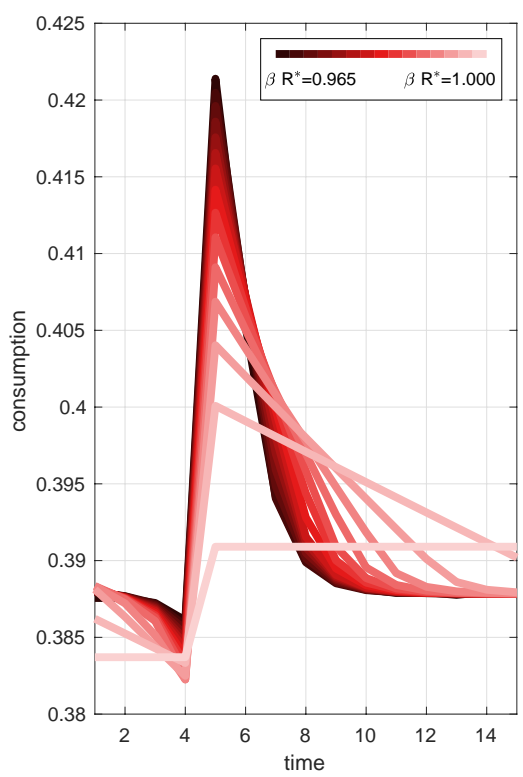

(c) Consumption, $\sigma=1$

Figure 5: Left panel: Total factor productivity. Middle panel: Capital stock in period 5 as a function of $\beta R^{*}$, no adjustment costs. Right panel: consumption dynamics for various values of $R$ and $\sigma=1$; darker color represents lower $R^{*}$.

performed.

The key term is the first term in the bracket that involves the Lagrange multipliers on the limited commitment constraint. It can be written as

$$
\frac{\mu_{t+1}}{1+\sum_{s=0}^{t+1} \mu_{s}}=1-\beta R_{t+1}^{*} \frac{U^{\prime}\left(c_{t+1}\right)}{U^{\prime}\left(c_{t}\right)} .
$$

For linear utility, this term is equal to $1-\beta R_{t+1}^{*}$ and so decreases with $R_{t+1}^{*}$ at rate $\beta$. For concave utility, it decreases with $R_{t+1}^{*}$ at a faster rate for the following reason. Low international interest rates are associated with a decreasing consumption when the limited commitment constraints are slack. The lower the international rate, the faster is the decline in consumption, as in Panel 5c, where darker color represents lower $R^{*}$. To satisfy the binding limited commitment constraint in period $t+1$, consumption $c_{t+1}$ must therefore be relatively higher for lower international rates. As a result, low international rates are associated with low marginal rate of substitution $\beta U^{\prime}\left(c_{t+1}\right) / U^{\prime}\left(c_{t}\right)$. This magnifies the effect of the international rates on the left-hand side of (20), which now decreases with $R_{t+1}^{*}$ at a rate higher than $\beta$. This dominates the last term in (19) and completely overturns the first-best result. As Panel 5b shows, this is true for all three levels of $\sigma$. 
However, the effect is stronger for lower elasticity of intertemporal substitution $1 / \sigma$, as expected.

In the presence of incomplete capital stock depreciation or adjustment costs, capital stock in other periods will be affected as well, stretching the impact of low interest rates to other periods, but the main result was unchanged in our examples. We have also constructed examples, where lower interest rate increases the set of binding incentive constraints. In such case, lower interest rates generate an additional downward pressure on capital stock in other periods.

\section{Data and Calibration}

Capital stock data. Empirical implementations of the neoclassical growth model for Argentina, as for many other countries, has been hindered by the lack of a capital stock series that could be trusted. In fact, Argentina's government statistical agencies do not report an official series for the capital stock. Thus, researchers need to construct their own series using the perpetual inventory method, starting from a year in the sufficiently distant past, for which it can be safely assumed that the capital stock was virtually zero. The extent to which the resulting capital stock series can be trusted hinges critically, however, on the availability of a sufficiently long investment series for the different components of the capital stock. In its absence, one needs to estimate the capital stock for a particular year in the not-too-distant past and then exploit more recently available investment data to construct the series for that stock going forward with the perpetual inventory method.

Kydland and Zarazaga (2007) used the first approach to construct a capital stock time series for the period 1950-1997. We adopt their capital stock series in our benchmark calibration. The details of their method can be consulted in the Appendix B of their paper. Here it suffices to say that those authors exploited the availability of investment series for machinery and equipment, as well as for structures, for Argentina since the year 1900, to build up the capital stock with the perpetual inventory method, assuming that its initial level that year was zero and applying "truncated geometric depreciation" schedule used by the Economic Commission for Latin America (ECLAC hereafter) in several studies for a similar purpose. Hofman (2000) has argued that, with such depreciation scheme, investment series that go back to the year 1900 can start delivering reliable series of the capital stock fifty years later, that is, since 1950 . 
Since that original capital stock series, referred hereafter as the $\mathrm{KZ}$ series, goes only until the year 1997, it was necessary to extend it for our purposes to the years 19982008, applying the same perpetual inventory methodology to the investment data in 1993 prices for the period 1997-2008 published by Argentina's official statistical agency, the Instituto Nacional de Estadísticas y Censos (INDEC). The paper refrains from using the investment series for subsequent years because, as is well known, in 2007 the agency lost its autonomy and the national accounts started to be manipulated for political considerations, to the point of raising serious suspicions about their accuracy. ${ }^{8}$ Since the investment series for the 1997-2008 period were reported in 1993 prices, it was necessary to convert to those prices the investment series in 1986 prices used by Kydland and Zarazaga. This was accomplished by applying retroactively to the value of each component of the investment series, that is, to the level of investment in machinery and equipment, residential structures and non-residential structures in the year 1997, the growth rates between consecutive years in the original series in 1986 prices.

The second approach for construction of the capital stock series has been used in the Penn World Tables, version 9.1. We use the alternative Penn World Table capital stock series, referred hereafter as the PWT series as a robustness check. The PWT series also applies the perpetual inventory method, but using investment series only since 1950, starting from the level of capital stock estimated for that year with the procedure described in Appendix C of Feenstra et al. (2015).

Figure 6a plots both estimates of the detrended capital stock for the 1980-2008 period. There are two obvious differences between those capital stock estimates. The first is that the capital stock of the PWT series is considerably higher than in the $\mathrm{KZ}$ series. The second is that the PWT series is smoother than the KZ series, and declines at a faster pace.

The reasons for these rather striking discrepancies are twofold. First, the procedure applied in the PWT to obtain the capital stock for 1950 delivers a value that is about 22 percent higher than the corresponding value induced in the $\mathrm{KZ}$ series by the perpetual inventory method. Second, the depreciation rates for the different components of the investment series assumed by the PWT are considerably lower than those implied by the ECLAC truncated geometric depreciation scheme that is used in constructing the

\footnotetext{
${ }^{8}$ The efforts of the following administration to correct the problem seem to have largely failed, judging from the warning posted as of September 23, 2019 in the INDEC's website, cryptically warning readers that "...the series published after January 2007 and until December 2015 must be treated with reservations..."
} 


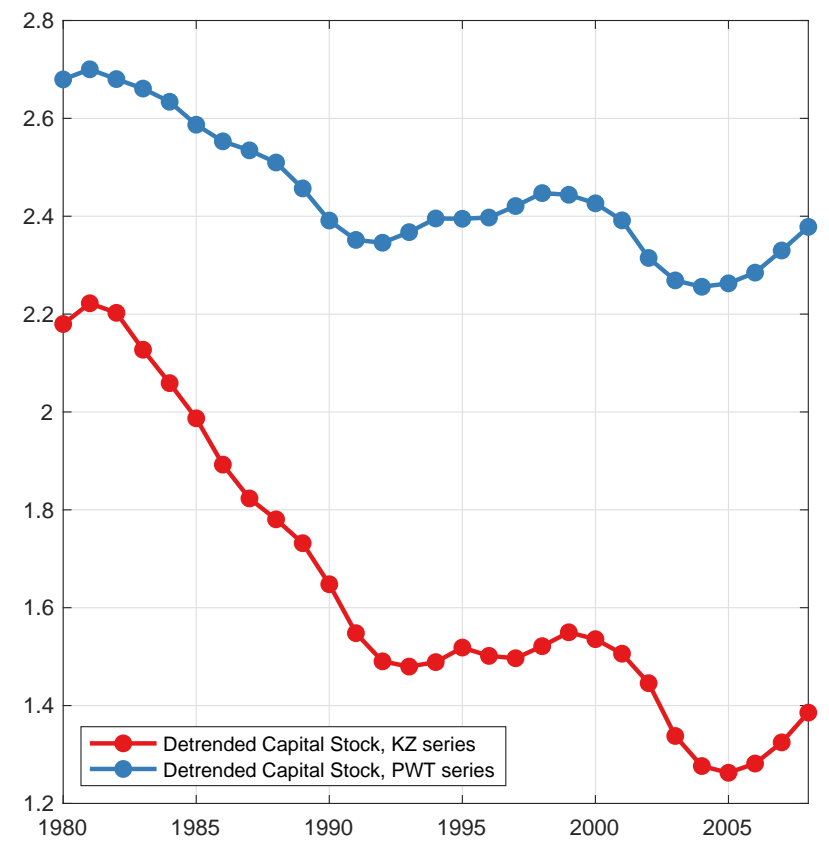

(a) Capital Stock

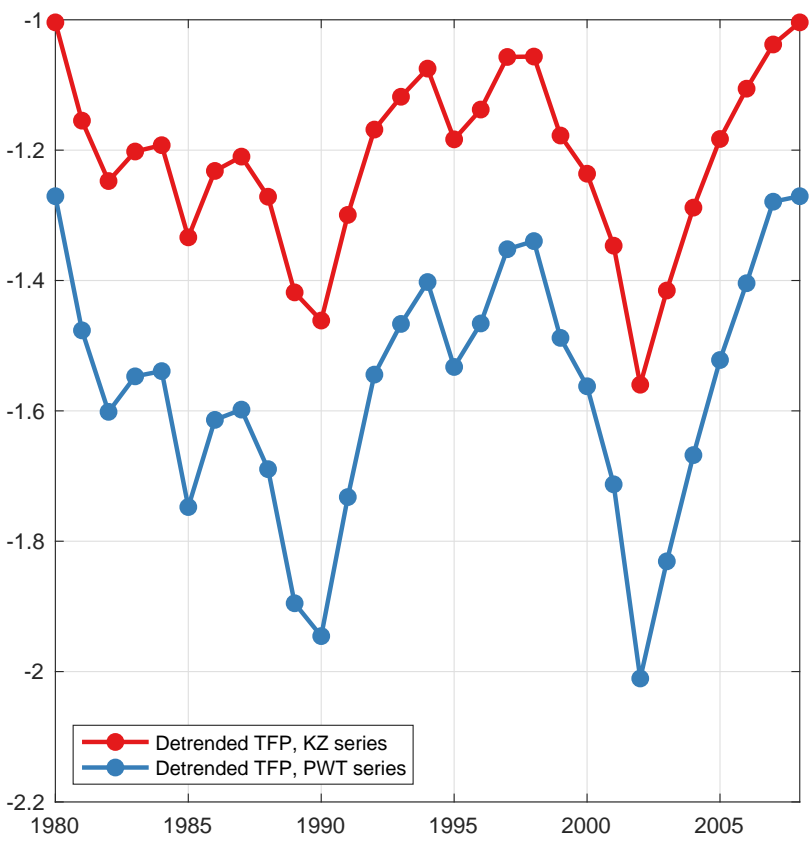

(b) Total Factor Productivity. Log index.

Figure 6: Total Factor Productivity and Capital Stock for Argentina, 1980-2008, detrended. KZ series versus Penn World Tables 9.1 series

$\mathrm{KZ}$ series. The reason is that, according to the ECLAC methodology, different assets cease to be productive after a certain number of years. In particular, that methodology assumes a useful life of 50 years for residential structures, 40 years for nonresidential structures, and 15 years for machinery and equipment. ${ }^{9}$ The finite lifetime assumption implies that, while still productive, machinery and equipment, nonresidential structures, and residential structures depreciate at the geometric rates of 16.5 percent, 8.81 percent, and 7.53 percent, respectively. ${ }^{10}$ As a result, the depreciation rate for any given year is a weighted average of the three depreciation rates just identified, with the weights equal to the share of the corresponding component on total investment. The resulting average depreciation rate over the period 1980-2008 adopted for the calibration is 11.7 percent. Note that this value is not far from that adopted in several papers in the business cycle

\footnotetext{
${ }^{9}$ As pointed out by Hofman in the abovementioned paper, these asset-life estimates are not too far from those that the U.S. Bureau of Economic Analysis has used in the past to estimate that country's capital stock.

${ }^{10}$ These depreciation rates stem from the fact that the residual value at a given period $t$ of an asset of type $i$ installed $j$ periods ago is given by $I_{t}\left(1-\delta_{i}\right)^{j}$, where $\delta_{i}$ is the depreciation rate of the asset, $I_{t}^{i}$ the period $t$ investment in the asset, and $j \leq \mathrm{T}$. Since the residual value of asset $i$ in the last year of its useful life is $I_{t}^{i} / T$, its geometric depreciation rate while still productive is obtained by solving the equation $I_{t}^{i}\left(1-\delta^{i}\right)^{T}=\frac{I_{t}^{i}}{T}$.
} 
literature, such as that by Kydland and Prescott (1982) and King and Rebelo (1999), among others.

In contrast, the PWT assumes that the different types of assets that make up total investment remain forever productive and, in addition, it applies to most of them geometric depreciation rates that are much lower than those implied by the ECLAC procedure. Of course, as in the case of the $\mathrm{KZ}$ series, the depreciation rate for every year is a weighted average of that of the different categories of assets included in total investment. The resulting PWT average depreciation rate for the period 1980-2008 under study is about 3.4 percent. The fact that this rate of obsolescence is less than a third of that of the $\mathrm{KZ}$ capital stock and moreover, that the source of investment data is the same for the underlying corresponding methodologies, explains why the PWT capital stock series doesn't fall as fast as the KZ series: the lower the depreciation rate, the more the same flow of investment adds to the not-yet-depreciated capital stock.

Working Age Population. Working age population, defined as individuals 20 to 69 years old, is also published by the INDEC. Since that source provides only quinquennial population estimates, the data for the intermediate years were obtained by geometric interpolation.

Output. We extended the output series from Kydland and Zarazaga (2007) for the years 1998-2008, with the data published by the INDEC in 1993 prices and expressed the entire series for the period 1980-2008 with the same procedure applied to the investment series outlined above.

Total Factor Productivity. This series was obtained from the output and capital stock series by applying to the production function (2) the standard growth accounting procedure, one for each of the two alternative values of the capital income share and capital stock series considered in the quantitative implementation of the model. The detrended TFP series were normalized by setting its value in 1980 to that which makes the average value of those series over the period 1980-2008 equal to the value of TFP in steady state, assumed to be 1 following standard practice. The corresponding detrended output and capital series were normalized by a common constant, such that the value of output would be 1 if the capital stock were at its steady state value in any particular year of the 1980-2008 period. Figure 6b plots the resulting TFP time series for both estimates of the 
capital stock. Apart from the level shift, both estimates are similar.

International Real Interest Rates. The real international interest rates were constructed from the same data sources used by Neumeyer and Perri (2005) and with their same procedure. Accordingly, the nominal interest rates series are the yields of the Merrrill Lynch's High Yield 175 U.S. Bond Index series and its successor, the Merrill Lynch's LowGrade Corporate Bond yields at different frequencies. The average quarterly values of these series between the first quarter of 1980 and the last one of 2008 were deflated by expected inflation with the approach followed by Neumeyer and Perri, that is, by the inflation rate of the GDP deflator in the corresponding quarter and the three preceding ones. The annual real international interest rates were calculated as the average of the four quarters of the corresponding year. The resulting time series for the international interest rate has been shown in Figure 2 in the introductory section.

\subsection{Calibration}

We calibrate the model for the Argentine economy as follows. We set the coefficient of relative risk aversion $\sigma=2$ and capital share $\theta=0.4$. Based on the 1980-2008 period, we compute the depreciation rate $\delta=0.117$, net growth rate of technology $\gamma=0.015$ and working age population growth rate $\eta=0.014$.

The steady state international risk free rate $R_{S S}^{*}$ is set to its average over the 19802008 period, which is 8.5 percent. We calibrate the discount factor $\beta$ to be such that the steady state capital-output ratio is equal to 1.656, its average over the 1980-2008 period. The capital-output ratio has varied considerably over time, and we will later provide robustness results for alternative values. The steady state capital-output ratio is lower than what can be supported in a first-best economy. As suggested by Proposition 1, the limited commitment constraints will bind in the steady state. The resulting equilibrium interest rate $R_{s s}$ faced by Argentina is 12.4 percent, which means that the steady state default rate is 3.53 percent. The steady state equilibrium interest rate in turn yields the discount factor $\beta=0.916$. Finally, we set the adjustment cost parameter $\kappa$ so as to match the volatility of investment over the 1980-2008 period to the data. This yields $\kappa=0.397$. The benchmark parameters are summarized in Table 1.

We run the experiment for the 1980-2008 period. We set the initial level of debt $d_{0}$ in 1980 to be zero, which is close to 3.2 percent of GDP, as computed by Lane and Milesi- 
Ferretti (2017). We feed in the actual time series for TFP, $\left\{a_{t}\right\}$ and assume that, after 2008 , it reverts back to its mean value.

Table 1: Benchmark Parameters

\begin{tabular}{llllllll}
\hline$\sigma$ & $\beta$ & $\delta$ & $\gamma$ & $\eta$ & $R_{S S}^{*}$ & $\kappa$ & $d_{1980} / y_{1980}$ \\
\hline 2.000 & 0.916 & 0.117 & 0.015 & 0.014 & 1.085 & 0.397 & 0 \\
\hline
\end{tabular}

Figure 7a shows the total factor productivity in Argentina for 1980-2008. After a relatively rapid decrease in the 1980's, Argentine TFP recovered for most of 1990s, with a mild exception in 1995, when TFP temporarily declined. The crisis between 1998 and 2002 is visible by another drastic decline in TFP. After that, TFP recovered again. Red dots in figure $7 \mathrm{~b}$ show periods when the limited commitment constraints bind: between 1991 and 1998, with the exception of 1995, and then after 2004. Those are periods when TFP is relatively high. As figure $7 \mathrm{~b}$ shows, binding limited commitment constraints imply that the capital stock is relatively low. In contrast, in the first-best economy, investors accumulate a large amount of capital: in the absence of the limited commitment constraints, capital stock would be about $40 \%$ higher, on average, between 1990 and 2008.

In other words, the calibrated model traces the decline that Argentina's capital stock experienced during the 1980s with remarkable accuracy because, as predicted by theory, the limited commitment constraints were almost never binding during that decade. At the same time, the limited enforcement frictions were often binding in the subsequent two decades, resulting in a capital stock, represented by the red line in Figure $7 \mathrm{~b}$, that accounts for between $50 \%$ and $85 \%$ of that stock missing from the Argentine economy in 1990s and 2000s, as captured by the distance between the blue and black lines in that same figure.

Notice also, as discussed in detail below, that the calibrated model is successful at replicating Argentina's capital stock asymmetric response to positive and negative changes of its total factor productivity and to its seemingly subdued reaction to lower international interest rates.

Response to TFP changes. Figure $7 \mathrm{~b}$ also shows how the capital stock responds asymmetrically to changes in productivity. While the decline in the 1980s is about the same as 


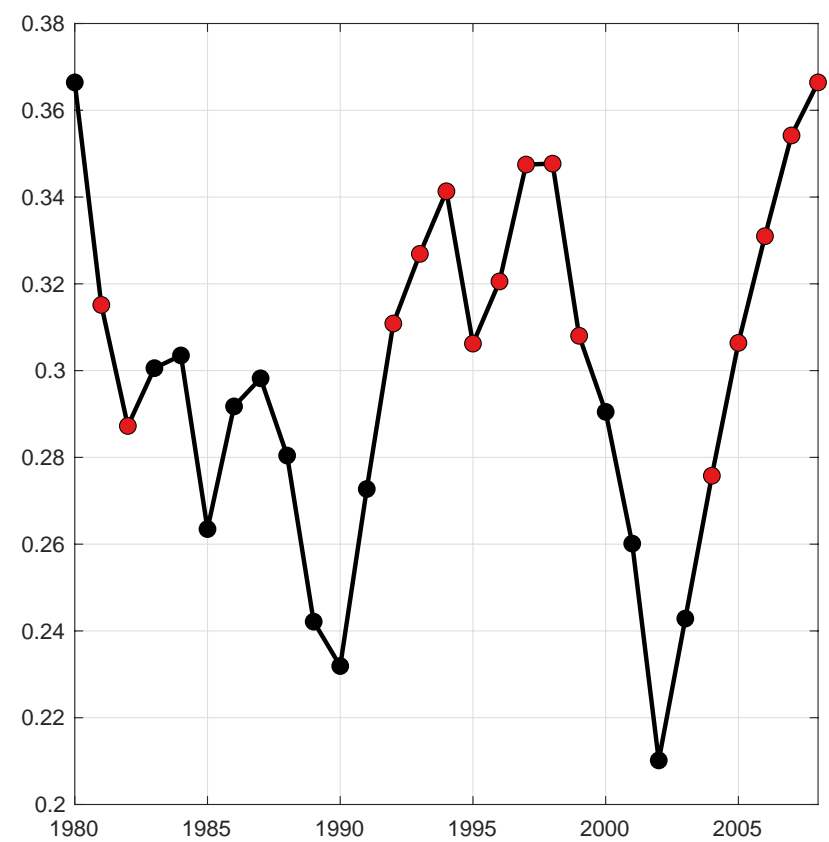

(a) Total Factor Productivity

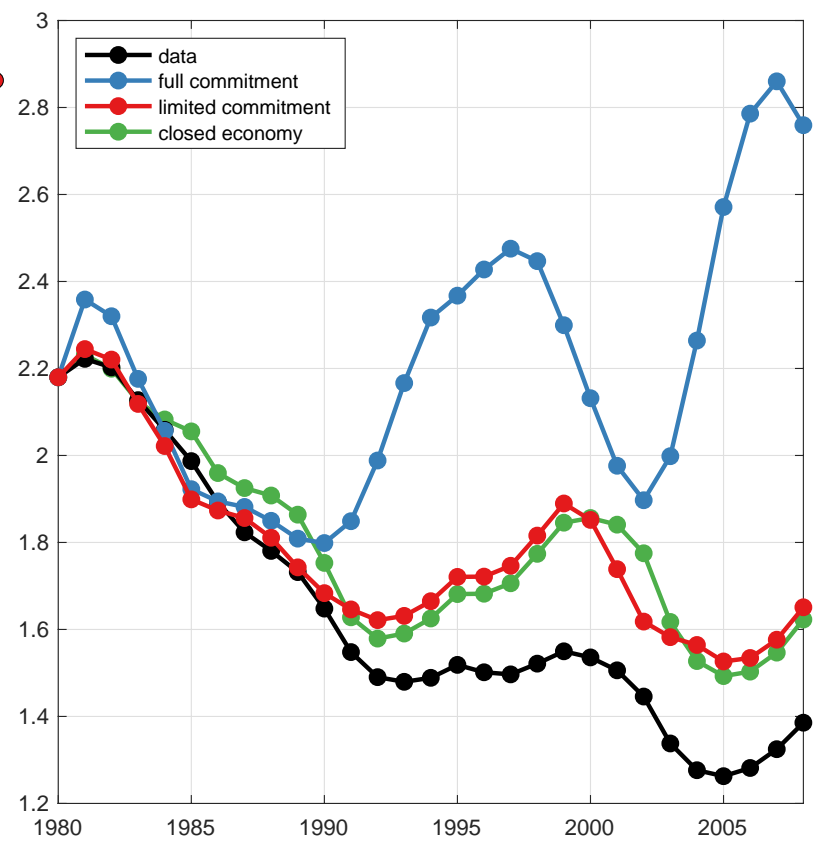

(b) Capital Stock

Figure 7: TFP and capital stock for Argentina, 1980-2008, benchmark calibration. Red dots in panel (a) denote years when the limited commitment constraint binds.

in a full commitment economy, the reversal in 1990s is substantially stronger in the full commitment economy. By 1994, capital stock in the full commitment economy has fully recovered to its 1980 level, but remains 24 percent below the 1980 level in the limited commitment economy. A similar pattern is repeated after 2002, when the capital stock increases rapidly above its 2002 level under full commitment, while under limited commitment it reaches its 2002 level only in 2008. The asymmetric response of the limited commitment economy is reminiscent of the closed economy, also depicted in Figure $7 \mathrm{~b}$, although both economies exhibit differences in its capital stock dynamics, especially in periods when the limited commitment constraint does not bind.

The role of international rates. Figure $7 \mathrm{a}$ shows that the limited commitment constraints were binding between 1992 and 1999, and then again between 2004 and 2008. Those time periods coincide with periods of low international interest rates, as shown in Figure 8a, which replicates the data from Figure 2 for convenience. The examples in section 5 suggest that the low interest rates should contribute to the decline of the capital stock, rather than increase it, as in an economy without commitment problems. To investigate this hypothesis, we consider an experiment where the interest rates after 1990 


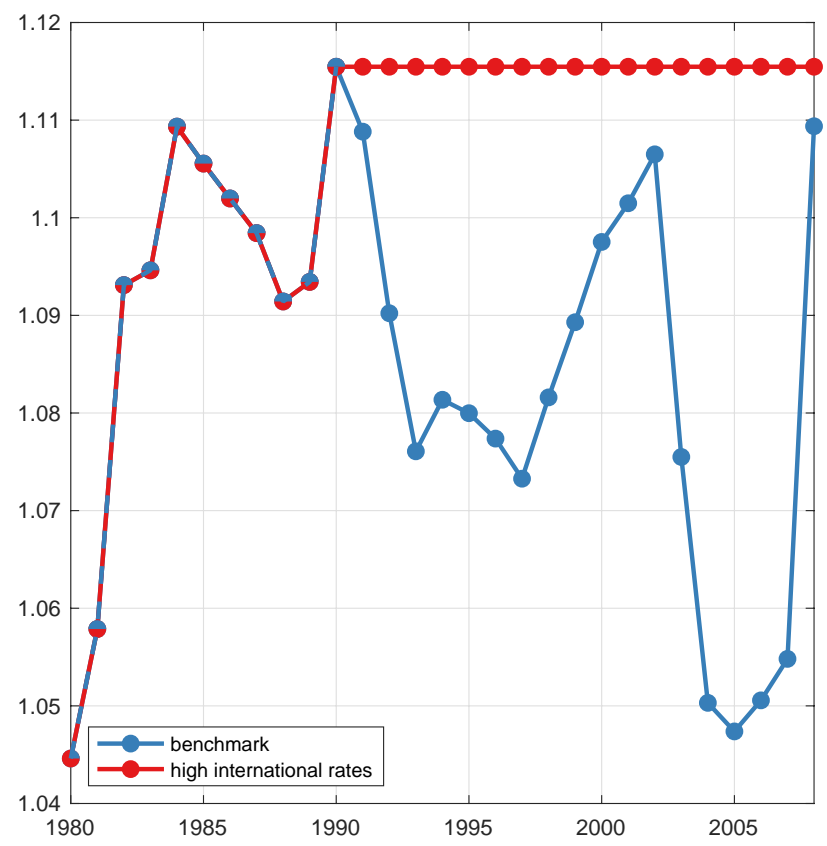

(a) Interest Rate

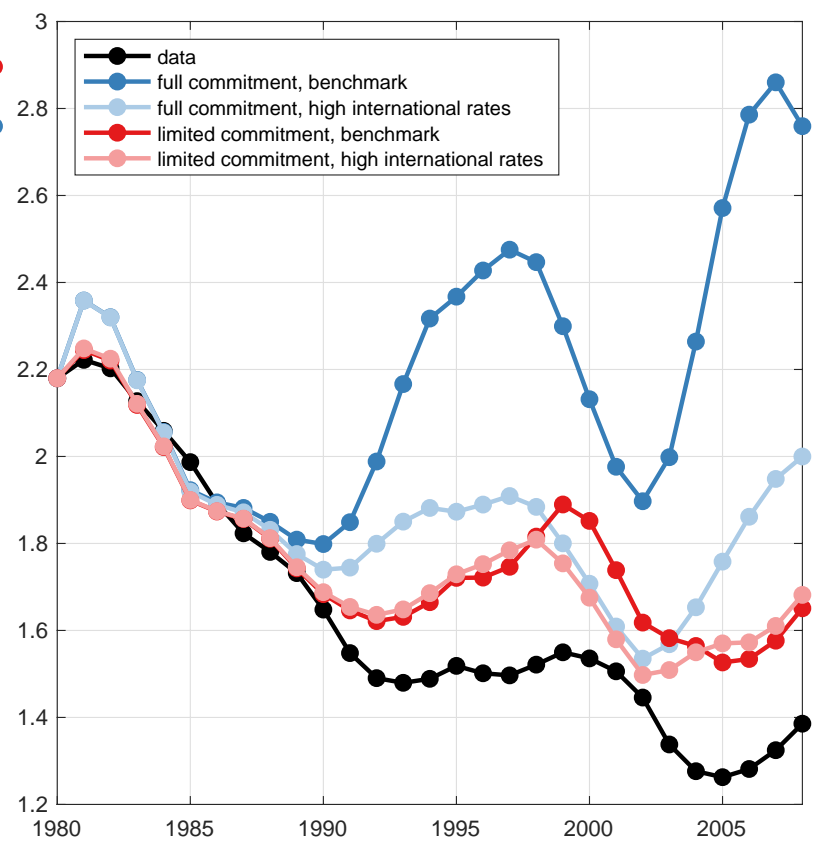

(b) Capital Stock

Figure 8: Capital stock in an economy with high international rates between 1991 and 2008.

stay forever at their 1990 level of 11.5 percent, higher than any interest rate afterwards. Figure $8 \mathrm{~b}$ shows the resulting capital stock. As conjectured, the capital stock between 1990 and 1997, and then between 2005 and 2008, would be higher than in a benchmark economy, even if marginally (for example, by 2 percent in 1997). Low interest rates thus contributed to the decrease of the capital stock, rather than its increase. In contrast, in the absence of the limited commitment friction, low interest rates would increase the capital stock substantially, for example by 30 percent in 1997.

Interestingly, the pattern is reversed in the interim period between 1999 and 2003, when the limited commitment constraints do not bind, and only the direct effect of interest rates is present. ${ }^{11}$ Lower interest rates increase the capital stock both in a limited commitment economy and in a full commitment economy. Note, however, that the increase is substantially larger in the economy with full commitment. That is because of the adjustment costs. Knowing that capital stock will decrease again in the near future, the agents in the limited commitment economy are reluctant to increase the capital stock by more. Thus, the second best effects "spill over" even to the periods when the limited

\footnotetext{
${ }^{11}$ In 1998, 1999 and 2004, the limited commitment constraints bind in the benchmark economy, but not in the economy with high interest rates.
} 


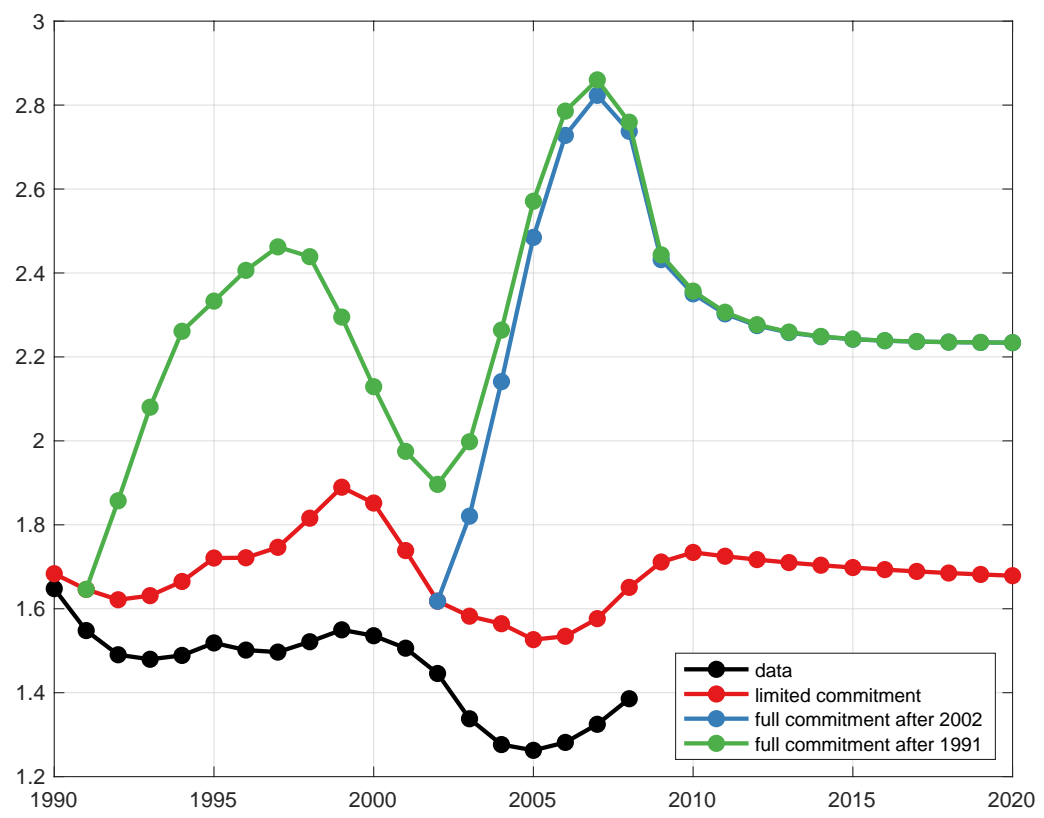

Figure 9: Capital stock in a second best economy, and in an economy where the limited commitment constraints are unexpectedly relaxed either in 1991 or in 2002.

commitment constraints do not bind and reduce the response of the capital stock.

\section{What if Argentina gains commitment?}

To the extent that the inability to commit to honor its external debt obligations is a feature inherent to Argentina's economy, that country seems doomed to stagnation. But the limited commitment constraints in the model economy can be thought of as a shortcut for a poor institutional configuration or social norms that prevent Argentina's governments, and the citizens who vote for them, to visualize the benefits of no longer belonging to the list of nations perceived as prone to "opportunistic defaults." Knowledge of the gains brought about by that change of perception in international credit markets could help to gather support for the structural reforms needed to remove Argentina from such a list.

Thus, suppose now that that nation, magically as it were, had implemented in 2003 those reforms. How much more capital would it have accumulated as a result? The answer is shown in Figure 9. There would be a gradual buildup of capital stock after 2000. The build-up would be substantial but, due to the adjustment cost, it would take about 15 years to get to the new steady state. The new steady state would have about 40 percent more capital stock than it would be in the presence of limited commitment 
constraints.

In the interim period, moreover, the capital stock would have been substantially higher, propped up by the surge of TFP observed over the period 2003-2008. In fact, in 2007, the capital stock would have been almost $80 \%$ above that of the economy with the limited commitment friction. The implication for workers is that their real wages, assuming the capital share of 0.4 adopted in the benchmark calibration, would have been that year a whopping $25 \%$ higher. Of course, this gain would have subsided over time,

as TFP reverted to its average. Real wages would have been, nevertheless, permanently higher by about $13 \%$ after the economy converged to the steady state of the economy with commitment.

A similar message emerges from performing the same exercise after 1991. In the year 2007 the capital stock and real wages would have been $40 \%$ and $15 \%$ higher, respectively, in the economy with commitment than without it. In fact, Argentine workers would have enjoyed real wages on average 13\% higher over the period 1992-2008, a gain that would persist over time, because it is the same associated with the higher capital stock of the economy free of the limited commitment friction.

\section{Sensitivity Analysis}

In this section we explore the robustness of our results to alternative assumptions about the capital-output ratio and about the capital stock.

Since the results are sensitive to the target capital-output ratio, we have targeted the steady-state capital-output ratio to 1.539 , which is the average capital-output ratio over the 1990-2008 period. This requires a slightly lower discount factor of 0.901. As a result, the limited commitment constraints now bind more often. Unlike in the benchmark scenario, they also bind in 1983, 1991, 2000 and 2003, and the difference between limited commitment economy and the closed economy is smaller. The capital stock is now closer to the data, however: in 2008, for example, it is about 10 percent higher than in the data, while the benchmark economy overshoots the data by about 20 percent. The remaining features of the capital stock dynamics are similar to the benchmark economy.

Second, we use capital stock estimates from the Penn World Tables 9.1 dataset. The differences from our benchmark dataset were described in Section 6. This requires a recalibration of the model: the depreciation rate is now 3.39 percent instead of 11.7 


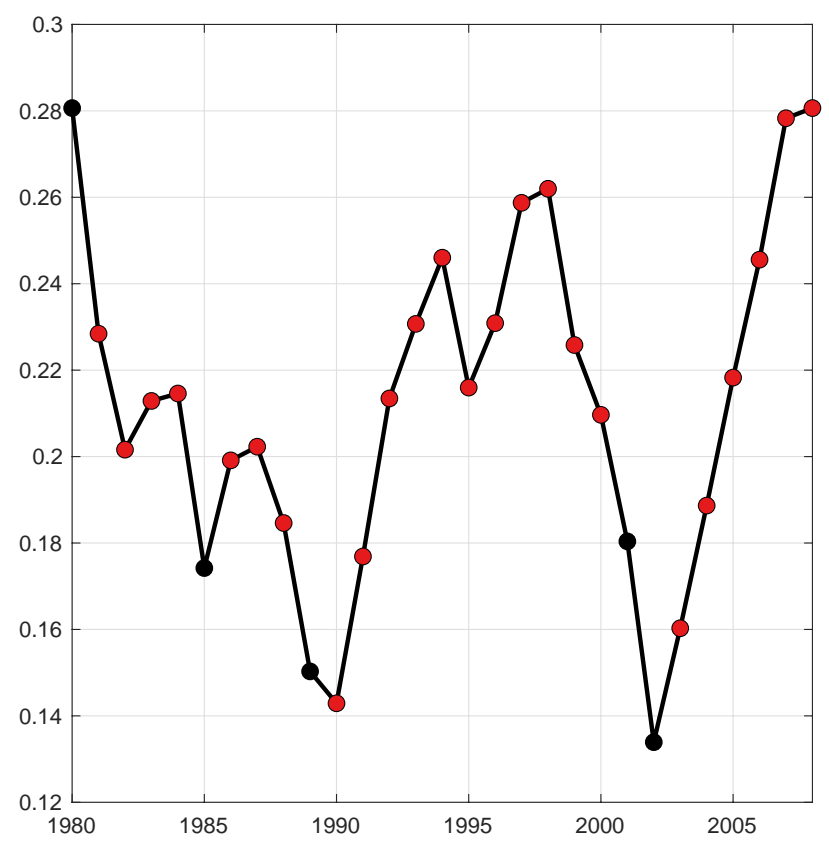

(a) Total Factor Productivity

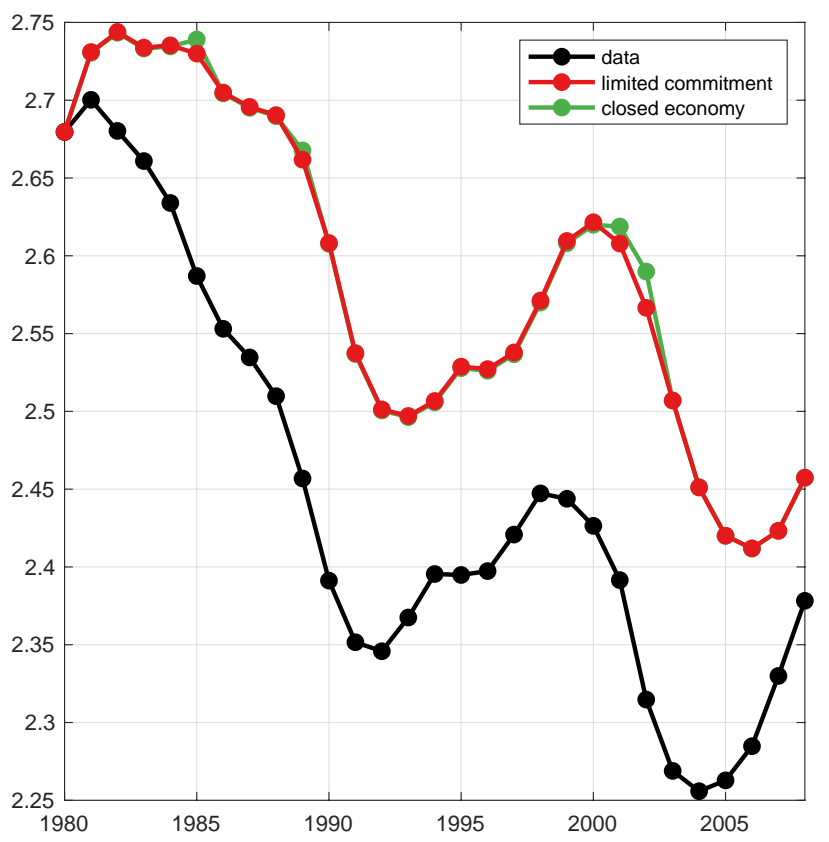

(b) Capital Stock

Figure 10: TFP and capital stock for Argentina, 1980-2008, Penn World Tables 9.1 data. Red dots in panel (a) denote years when the limited commitment constraint binds.

percent, and the steady state capital to output ratio is 2.896 instead of 1.656. In addition, the long-run growth rate $\gamma$ is reduced to 1 percent instead of 1.5 percent. This requires a substantial recalibration of the adjustment costs, that are now equal to 5.777, about 15 times higher than in the benchmark calibration, and of the discount factor, which is now 0.870 .

Figure 10 shows the results. Due to a higher discount factor, the limited commitment constraints are now binding significantly more often. The only periods when they do not bind are 1985, 1989 and then 2001 and 2002. The capital stock is now much closer to the capital stock in the closed economy, with small deviations around 1985 and 2000. Nevertheless, the alternative calibration is still able to explain a substantial decrease of the capital stock in the 1980's, and the growth rate of the capital stock in the 1990's is about as fast as in the data, in contrast to the full commitment economy, which substantially overshoots the capital stock throughout the whole period (not shown in the picture). 


\section{Final remarks}

This paper has been motivated by the desire to identify some of the factors potentially responsible for the secular economic decline of Argentina, a country that belonged to the exclusive club of the top ten richest nations in the world at the beginning of the 20th century, only to descend to the status of mediocrity at the end of it.

A useful clue in this endeavor were empirical regularities observed in the responses of that country's capital stock to changes in total factor productivity and international real interest rates in the period 1980-2008. Particularly noticeable is the asymmetric nature of those responses to decreases and increases of TFP, and the fact that the international real interest rates declined contemporaneously with the rising TFP observed in the mid 1990s and mid 2000s, yet they failed to boost capital accumulation in Argentina.

Our findings show that a model with limited commitment constraints, calibrated to Argentina's economy, can account for both of those features, and replicate Argentina's capital stock rather well. Sepcifically, the model can account not only for that country's capital shallowing in the lost decade of the 1980s, but also for the failure of its capital stock to show any significant recovery between 1992-1998 and 2002-2008, when TFP grew strongly and international interest rates were low by historical standards. The relatively good quantitative performance of the model is especially noteworthy given that the paper stays away from introducing exogenous costs of default to improve the matching between the model predictions and the data, as most of the existing literature does.

At the same time, the model generates several predictions that do not fit data well. First, it produces the counterfactural result that net exports will be procyclical, when they are acyclical or countercyclical in the data. The inability of limited commitment models to match data along this dimension is well known. Second, as the decentralization of the model shows, the intertemporal wedge $\Delta_{t+1}$ must be implemented by means of a capital income tax. We do not have any evidence that such a tax has been implemented. However, the quantitative analysis has revealed that the intertemporal wedge is rather small. It is therefore likely that a version without the capital wedge will produce results that are quantitatively similar.

In any case, the paper demonstrates the overall ability of the limited commitment constraints to account for the capital that seems to be typically missing from Argentina's economy under unusually favorable domestic and international conditions. This finding 
questions the often-expressed view that the limited enforcement friction doesn't play a quantitatively important role in accounting for important aspects of the evidence of small open economies.

A future research agenda should examine if a stochastic version of the model economy studied in this paper, appropriately extended to include, for example, endogenous labor input, can do an equally good job at accounting for other dimensions of the evidence not explicitly considered in this paper.

\section{References}

Aguiar, M. and M. Amador (2011). Growth in the shadow of expropriation. The Quarterly Journal of Economics 126(2), 651-697. 3, 5, 9, 20

Aguiar, M., M. Amador, and G. Gopinath (2009). Investment cycles and sovereign debt overhang. Review of Economic Studies 76(1), 1-31. 5, 6, 9

Albuquerque, R. and H. A. Hopenhayn (2004). Optimal lending contracts and firm dynamics. Review of Economic Studies 71(2), 285-315. 5

Chari, V. V. and P. J. Kehoe (1990). Sustainable plans. Journal of Political Economy 98, 783-802. 17

Dovis, A. (2018). Efficient sovereign default. The Review of Economic Studies 86(1), 282-312. 5,6

Feenstra, R. C., R. Inklaar, and M. P. Timmer (2015). The next generation of the penn world table. American economic review 105(10), 3150-82. 24

Gordon, G. and P. A. Guerron-Quintana (2018). Dynamics of investment, debt, and default. Review of Economic Dynamics 28, 71-95. 7

Hofman, A. A. (2000). Standardised capital stock estimates in latin america: a 1950-94 update. Cambridge Journal of Economics 24(1), 45-86. 23

Kehoe, P. J. and F. Perri (2002). International business cycles with endogenous incomplete markets. Econometrica 70(3), 907-928. 1, 5 
Kehoe, P. J. and F. Perri (2004). Competitive equilibria with limited enforcement. Journal of Economic Theory 119, 184-206. 3, 5, 9, 12, 17, 37, 42

King, R. G. and S. T. Rebelo (1999). Resuscitating real business cycles. Handbook of macroeconomics 1, 927-1007. 26

Kydland, F. E. and E. C. Prescott (1982). Time to build and aggregate fluctuations. Econometrica: Journal of the Econometric Society, 1345-1370. 26

Kydland, F. E. and C. E. Zarazaga (2007). Argentina's lost decade and the subsequent recovery puzzle. In T. J. Kehoe and E.C.Prescott (Eds.), Great Depressions of the Twentieth Century, pp. 191-216. Minneapolis, MN: Federal Reserve Bank of Minneapolis. 3, 23, 26

Lane, P. R. and G. M. Milesi-Ferretti (2017). International financial integration in the aftermath of the global financial crisis. IMF Working Paper (WP/17/115), 223 - 250. 27

Marcet, A. and R. Marimon (1992). Communication, commitment, and growth. Journal of Economic Theory 58, 219-249. 5

Neumeyer, P. A. and F. Perri (2005). Business cycles in emerging economies: the role of interest rates. Journal of Monetary Economics 52(2), 345-380. 1, 6, 27, 37

Rebelo, S., N. Wang, and J. Yang (2018). Rare disasters, financial development, and sovereign debt. Technical report, National Bureau of Economic Research. 7

Restrepo-Echavarria, P. (2019). Endogenous borrowing constraints and stagnation in Latin America. Journal of Economic Dynamics and Control (forthcoming). 5, 6

Thomas, J. and T. Worrall (1994). Foreign direct investment and the risk of expropriation. Review of Economic Studies 61, 81-108. 5

Tsyrennikov, V. (2013). Capital flows under moral hazard. Journal of Monetary Economics 60(1), 92-108. 5, 6 


\section{A Appendix For Online Publication: Equilibrium Con- cepts}

\section{A.1 Self Enforcing Equilibrium}

We assume that individuals in the country borrow and lend directly from abroad using one period bonds. Let $b_{t}$ denote the country's outside debt borrowed in period $t$ and due in period $t+1$. If $b_{t+1}>0$ then the representative agent is borrowing, while if $b_{t+1}<0$, the representative agent is saving. The initial debt position $b_{0}$ is exogenously given. The resource constraint for the country is

$$
c_{t}+(1+\gamma)(1+\eta)\left(k_{t+1}-b_{t+1}\right)+\phi\left(k_{t}, k_{t+1}\right)=f\left(a_{t}, k_{t}\right)+(1-\delta) k_{t}-R_{t} b_{t}
$$

To introduce default decisions, we follow Kehoe and Perri (2004) and Neumeyer and Perri (2005) by assuming that the government collects repayments from the agents to pass them on to foreigners, and can default on them if it chooses so. If it defaults, the proceeds are rebated back to the agents. The default rate rule for the next period, $\tau_{t+1} \in[0,1]$, specifies a fraction of the debt that the country does not repay. Since the government defaults when the representative is borrowing, we restrict attention to cases when $\tau_{t+1}$ is zero for $b_{t+1}<0$. At the beginning of the next period the debt net of the defaulted amount is thus given by $\left(1-\tau_{t+1}\right) b_{t+1}$.

In addition to the default decisions, the government can tax capital in period $t$ at a rate $\tau_{t}^{K} \leq 1$. The government's budget is balanced each period and the government transfers the confiscated portion of debt back, as well as the capital tax revenue, to its citizens via a lump-sum transfer $T_{t}$. The government's budget constraint is

$$
T_{t}=\tau_{t} R_{t} b_{t}+\tau_{t}^{K}\left(f_{k, t}-\delta\right)
$$

where $R_{t}$ is the interest rate that Argentina faces (possibly distinct from the international interest rate $R_{t}^{*}$ ).

Households. The representative agents choose consumption $c_{t}$, next period capital $k_{t+1}$, and the amount of foreign borrowing $b_{t+1}$. They supply one unit of labor inelastically, and rent capital to the representative firm. The interest rate on the debt between period $t$ and $t+1$ is denoted by $R_{t+1}$, and the agents earn a return on capital after cap- 
ital taxes and depreciation $r_{t}$, and a wage rate $w_{t}$. The representative agent takes the sequence of wages $\left\{w_{t}\right\}$, returns to capital $\left\{r_{t}\right\}$ and interest rates $\left\{R_{t+1}\right\}$ as given.

The representative agent enters the period with the net debt $R_{t} b_{t}$. Since the agent is not allowed to default himself, he repays the full amount of the debt. As will be clear later, the interest rate $R_{t}$ will, however, reflect the default decisions of the government. The budget constraint is

$$
c_{t}+(1+\eta)(1+\gamma)\left(k_{t+1}-b_{t+1}\right)+\phi\left(k_{t}, k_{t+1}\right)=w_{t}+r_{t} k_{t}-R_{t} b_{t}+T_{t} .
$$

Note that, since the representative agent, and not the firm, own the capital, the adjustment costs are borne directly by the representative agent. The household's problem is to maximize their lifetime utility (3) subject to the sequence of budget constraints (23), taking the initial capital stock $k_{0}$ and debt $b_{0}$ as given.

Firms. The representative firm maximizes profits taking the wage rates and rental rates of capital as given. As usual, the profit maximization can be characterized by the first order conditions in capital and labor. This yields the following conditions for the wage rate and the return to capital:

$$
\begin{aligned}
w_{t} & =f\left(a_{t}, k_{t}\right)-k_{t} f_{k}\left(a_{t}, k_{t}\right) \\
r_{t} & =1+\left(1-\tau_{t}^{k}\right)\left(f_{k}\left(a_{t}, k_{t}\right)-\delta\right) .
\end{aligned}
$$

International lender. The risk neutral lender can transform resources at the risk free rate $R_{t}^{*}$ over time. However, he faces the possibility that the country will default on its debt. The lender maximizes the present value of profits, given by

$$
\sum_{t=0}^{\infty} Q_{t}^{*}(1+\gamma)^{t}(1+\eta)^{t}\left[-(1+\eta)(1+\gamma) b_{t+1}+R_{t}\left(1-\tau_{t}\right) b_{t}\right]
$$

The lender takes the government's policy, as well as the interest rate $\left\{R_{t}\right\}$ and $b_{0}$ as given, similarly to the agents. The equilibrium interest rate must equate the marginal cost of lending $R_{r+1}^{*}$ to the marginal benefit: $\left(1-\tau_{t+1}\right) R_{t+1}$

$$
R_{t+1}=\frac{R_{t+1}^{*}}{1-\tau_{t+1}}
$$


Equilibrium. In what follows, we consider self-enforcing equilibria, where the equilibrium value of consumption is equal or exceeds the value of moving to autarky, and so the limited commitment constraint (7) holds. To simplify notation, let $\pi=\left\{\pi_{t}\right\}$ where $\pi_{t}=\left(\tau_{t}, \tau_{t}^{K}\right)$ be the government policy, $x=\left\{x_{t}\right\}$ where $x_{t}=\left(c_{t}, k_{t+1}, b_{t+1}\right)$ be the allocation, and $p=\left\{p_{t}\right\}$ where $p_{t}=\left(w_{t}, r_{t}, R_{t}\right)$ be the prices. We define the self-enforcing equilibrium as follows:

Definition 2. A self-enforcing equilibrium consists of sequences $(\pi, x, p)$ such that, given exogenous sequences $\left\{a_{t}, R_{t}^{*}\right\}$, initial debt $b_{0}$, and initial capital $k_{0}$,

i. $x$ solves the representative agent's problem taking $\pi$ and $p$ as given,

ii. $p$ satisfies the representative firm's conditions (24), and the lender's condition (25),

iii. government budget constraint (22) holds,

iv. the limited commitment constraint (7) holds.

There are four conditions that characterize the representative agent's problem in the competitive equilibrium. The first-order condition in bonds gives the Euler equation for consumption:

$$
U^{\prime}\left(c_{t}\right)=\frac{\beta}{(1+\gamma)^{\sigma}} R_{t+1} U^{\prime}\left(c_{t+1}\right)
$$

For the capital sequence to be chosen optimally by the agents, the net after-tax return on capital has to be equal to the return on bonds,

$$
R_{t+1}\left(1+\phi_{2, t}\right)=1+\left(1-\tau_{t+1}^{k}\right)\left(f_{k, t+1}-\delta\right)-\phi_{1, t+1},
$$

and the transversality condition for capital must hold

$$
\lim _{t \rightarrow \infty}\left[\frac{(1+\gamma)(1+\eta)}{R^{*}}\right]^{t} k_{t+1}=0
$$

Finally, the no-Ponzi condition for debt must hold in equilibrium:

$$
\lim _{t \rightarrow \infty}\left[\frac{(1+\gamma)(1+\eta)}{R^{*}}\right]^{t} b_{t+1}=0
$$




\section{A.2 Decentralizing the efficient allocations.}

Suppose that the allocation $\left\{c_{t}, k_{t+1}, t r_{t}\right\}$, as well as the corresponding Lagrange multipliers $\left\{\mu_{t}\right\}$ are Pareto efficient, and consider the following government policy. The country's government defaults next period at a rate

$$
\tau_{t+1}=\frac{\mu_{t+1}}{1+\sum_{s=0}^{t+1} \mu_{s}} .
$$

The default rate sequence $\left\{\tau_{t}\right\}$ is always between zero and one. It is zero if the limited commitment constraint does not bind, and strictly positive otherwise. If the default rate is set according to (30), the Pareto efficient consumption sequence will satisfy the competitive equilibrium Euler equation (26), with $R_{t+1}$ determined by (25). The default rate (30) is designed in a way that the equilibrium interest rate $R_{t+1}$ is high exactly in the periods when the limited commitment constraint binds, and the marginal rate of substitution of the country's agents is low. The inverse of the interest rate $1 / R_{t+1}$ then exactly matches the low marginal rate of intertemporal substitution of the borrower.

The capital income tax rate sequence $\left\{\tau_{t}^{k}\right\}$ is defined to satisfy the following equality:

$$
\frac{U^{\prime}\left(c_{t}\right)}{\beta(1+\gamma)^{-\sigma} U^{\prime}\left(c_{t+1}\right)}\left(1+\phi_{2, t}\right)=1+\left(1-\tau_{t+1}^{k}\right)\left(f_{k, t+1}-\delta\right)-\phi_{1, t+1} .
$$

We will now decentralize the Pareto efficient allocation as a competitive equilibrium with government policy $\pi=\left\{\tau_{t}, \tau_{t}^{k}\right\}$. The candidate price system is given by (24) and (25). What remains to be defined is the initial debt $b_{0}$, and debt positions $\left\{b_{t+1}\right\}$. We set

$$
b_{t}=\frac{1}{R_{t}^{*}} \sum_{s=0}^{\infty} \frac{Q_{t+s}^{*}}{Q_{t}^{*}}(1+\gamma)^{s}(1+\eta)^{s} t r_{t+s}, \quad t=0, \ldots, \infty
$$

Lemma 1. Let $\left\{c_{t}, k_{t+1}, t r_{t}\right\}$ be the constrained efficient allocation. Suppose that the government chooses the default rates and the capital income tax rates $\pi=\left\{\tau_{t}, \tau_{t}^{k}\right\}$ according to (30) and (31). Let $x=\left\{c_{t}, k_{t+1}, b_{t+1}\right\}$, where $\left\{b_{t}\right\}$ is given by (32). Let also $p$ be given by (24) and (25). Then $(\pi, x, p)$ is a self-enforcing equilibrium given $\left\{R_{t}^{*}, a_{t}\right\}, b_{0}$ and $k_{0}$.

Proof. We first verify that the equilibrium allocation is budget feasible. First, note that the bond sequence defined by (32) is finite because of Assumption 1, and because the 
transfer sequence $\left\{t r_{t}\right\}$ is a bounded sequence. One can write

$$
R_{t}^{*} b_{t}=t r_{t}+(1+\eta)(1+\gamma) b_{t+1}
$$

and substitute away the transfers from the resource constraint (5) to get

$$
\begin{aligned}
c_{t}+(1+\eta)(1+\gamma) k_{t+1}+\phi\left(k_{t}, k_{t+1}\right) & =f\left(a_{t}, k_{t}\right)+(1-\delta) k_{t}-t r_{t} \\
& =f\left(a_{t}, k_{t}\right)+(1-\delta) k_{t}-R_{t}^{*} b_{t}+(1+\eta)(1+\gamma) b_{t+1} .
\end{aligned}
$$

Hence,

$$
\begin{aligned}
& c_{t}+(1+\eta)(1+\gamma)\left(k_{t+1}-b_{t+1}\right)+\phi\left(k_{t}, k_{t+1}\right) \\
& =f\left(a_{t}, k_{t}\right)+(1-\delta) k_{t}-R_{t}^{*} b_{t} \\
& =f\left(a_{t}, k_{t}\right)-f_{k, t} k_{t}+f_{k, t} k_{t}+(1-\delta) k_{t}-R_{t}\left(1-\tau_{t}\right) b_{t} \\
& =f\left(a_{t}, k_{t}\right)-f_{k, t} k_{t}+\left[1+\left(f_{k, t} k_{t}-\delta\right)\left(1-\tau_{t}^{k}\right)\right] k_{t}+\left(f_{k, t} k_{t}-\delta\right) \tau_{t}^{k} k_{t}+R_{t} \tau_{t} b_{t}-R_{t} b_{t} \\
& =w_{t}+r_{t} k_{t}+T_{t}-R_{t} b_{t},
\end{aligned}
$$

where the second equality adds and subtracts $f_{k, t} k_{t}$ and uses the definition of $R_{t}(25)$, the third one adds and subtracts $\left(f_{k, t} k_{t}-\delta\right) \tau_{t}^{k} k_{t}$, and the fourth one uses the expressions for $w_{t}$ and $r_{t}$ in (24) and the government budget constraint (22). Thus, the allocation $\left\{c_{t}, k_{t+1}, b_{t+1}\right\}$ is budget feasible given $b_{0}$.

Since $R_{t+1}$ is given by (25) and the default rate $\tau_{t+1}$ is given by (30), (9) implies that $\left\{c_{t}\right\}$ satisfies the Euler equation (26). Similarly, the definition of the capital income tax rate (31) and the first-order condition (10) imply that the first-order condition for capital (27) holds. The transversality condition (28) holds directly because the optimal capital stock satisfies (11), while the transversality condition (29) holds because the sequence of bonds $\left\{b_{t}\right\}$ is bounded and by Assumption 1. Thus, condition $i$. of the definition of the competitive equilibrium holds.

By definition of prices (24) and (25), condition ii. of the definition of the competitive equilibrium holds. The government budget constraint holds by Walras law, and so condition iii. is satisfied as well. Finally, condition $i v$. holds directly because the Pareto-efficient allocation satisfies (7). 


\section{A.3 Sustainable Equilibrium}

The self-enforcing equilibrium takes the government decisions as given. We will now make the government's decisions endogenous. We again follow closely Kehoe and Perri (2004).

We assume that the government chooses its period-t policy at the beginning of period $t$ and cannot commit to a particular policy in advance. After the government chooses its policies, agents make their decisions and prices are determined. Let $h_{t-1}=$ $\left\{\pi_{0}, \ldots, \pi_{t-1}\right\} \in H_{t-1}$ be the history of government policies up to period $t$, where $\pi_{t}=\left(\tau_{t}, \tau_{t}^{K}\right)$. Government's policy choice, agents' decisions, and the price system are all defined to be function of past history. Government's policy choice at the beginning of period $t$ after history $h_{t-1}$ is $\Pi_{t}\left(h_{t-1}\right)$, where $\Pi_{t}\left(h_{t-1}\right)=\left(\tau_{t}\left(h_{t-1}\right), \tau_{t}^{K}\left(h_{t-1}\right)\right)$. Prices are $P_{t}\left(h_{t}\right)$, where $P_{t}\left(h_{t}\right)=\left(w_{t}\left(h_{t}\right), r_{t}\left(h_{t}\right), R_{t}\left(h_{t}\right)\right)$. The agents' decisions are $X_{t}\left(h_{t}\right)$, where $X_{t}\left(h_{t}\right)=\left(c_{t}\left(h_{t}\right), k_{t+1}\left(h_{t}\right), b_{t+1}\left(h_{t}\right)\right)$. We denote the whole history-contingent sequence of the government's decisions by $\Pi=\left\{\Pi_{t}\left(h_{t-1}\right), h_{t-1} \in H_{t-1}\right\}$, of the agents' decisions by $X=\left\{X_{t}\left(h_{t}\right), h_{t} \in H_{t}\right\}$, and of prices by $P=\left\{P_{t}\left(h_{t}\right), h_{t} \in H_{t}\right\}$. Occasionally, we will denote the components of $X$ or $P$ similarly. We call the triplet $(\Pi, X, P)$ a plan. Furthermore, we define a continuation of the policy plan ${ }_{t} \Pi\left(h_{t-1}\right)$ to be the government's plan that follows history $h_{t-1},{ }_{t} \Pi\left(h_{t-1}\right)=\left\{\Pi_{t+s}\left(h_{t-1}, h_{s}\right), h_{s} \in H_{s}\right\}_{s \geq 0}$. Similarly, we define the continuation of the household plan that follows history $h_{t}$ by ${ }_{t} X\left(h_{t}\right)=\left\{X_{t+s}\left(h_{t}, h_{s}\right), h_{s} \in H_{s}\right\}_{s \geq 0}$.

Households. The agents' decisions are required to be optimal after any history, taking the price plan and the policy plan as given. That is, given government's plan $\Pi$ and the price plan $P$, the household plan $X$ must be such that the continuation of the plan ${ }_{t} X\left(h_{t}\right)$ solves, for all $t$ and $h_{t}$, the agent's problem

$$
\max _{\left\{c_{t+s}, k_{t+s+1}, b_{t+s+1}\right\}_{s=0}^{\infty}} \sum_{s=0}^{\infty} \hat{\beta}^{s} U\left(c_{t+s}\right)
$$

subject to the budget constraint

$$
\begin{aligned}
c_{t+s}+(1+\eta)(1+\gamma)\left(k_{t+s+1}-b_{t+s+1}\right) & =w_{t+s}\left(h_{t+s}\right)+r_{t+s}\left(h_{t+s}\right) k_{t+s}-R_{t+s}\left(h_{t+s}\right) b_{t+s} \\
& +T_{t+s}\left(h_{t+s}\right)-\phi\left(k_{t+s}, k_{t+1}\right) \quad s \geq 0,
\end{aligned}
$$


where $h_{t+s}$ is induced by the $\Pi$ according to $h_{t+s+1}=\left(h_{t+s}, \Pi_{t+s}\left(h_{t+s}\right)\right), k_{t}=k_{t}\left(h_{t-1}\right)$ and $b_{t}=b_{t}\left(h_{t-1}\right)$ are given, and the transfers are given as residuals from the government budget constraint,

$$
T_{t}\left(h_{t}\right)=\tau_{t}\left(h_{t}\right) R_{t}\left(h_{t}\right) b_{t}\left(h_{t-1}\right)+\tau_{t}^{K}\left(h_{t}\right)\left[f_{k, t}\left(a_{t}, k_{t}\left(h_{t-1}\right)-\delta\right]\right.
$$

Firms. The wage rates and the rental rates are derived in the standard way from the representative firm's and lender's problem. It must satisfy

$$
\begin{aligned}
w_{t}\left(h_{t}\right) & =f\left(a_{t}, k_{t}\left(h_{t-1}\right)\right)-k_{t}\left(h_{t-1}\right) f_{k}\left(a_{t}, k_{t}\left(h_{t-1}\right)\right) \\
r_{t}\left(h_{t}\right) & =1+\left[1-\tau_{t}^{k}\left(h_{t-1}\right)\right]\left(f_{k}\left(a_{t}, k_{t}\left(h_{t-1}\right)-\delta\right)\right.
\end{aligned}
$$

International lender. Taking the prices $P$ as given, the international lender solves, for all $t$ and $h_{t}$, the profit maximization problem. The continuation bond plan ${ }_{t} b\left(h_{t}\right)$ must maximize

$$
\sum_{s=0}^{\infty} \frac{Q_{t+s}^{*}}{Q_{t}^{*}}(1+\gamma)^{s}(1+\eta)^{s}\left[-(1+\eta)(1+\gamma) b_{t+s+1}+R_{t+s}\left(h_{t+s}\right)\left(1-\tau_{t+s}\left(h_{t+s-1}\right)\right) b_{t+s}\right],
$$

where $h_{t+s}$ is again induced by $\Pi$ according to $h_{t+s+1}=\left(h_{t+s}, \Pi_{t+s}\left(h_{t+s}\right)\right)$, and $b_{t}=$ $b_{t}\left(h_{t-1}\right)$ is given. This leads to a necessary condition for the price of bond,

$$
R_{t}\left(h_{t}\right)=\frac{R_{t}^{*}}{1-\tau_{t}\left(h_{t-1}\right)} .
$$

Government. Just like the households' decisions, the government's decisions must be optimal after any history. That is, the government's plan $\Pi$ must be such that the continuation policy plan ${ }_{t} \Pi\left(h_{t-1}\right)$ must solve, for any $t$ and any history $h_{t-1}$,

$$
\max _{\left\{\pi_{t+s}\right\}_{s=0}^{\infty}} \sum_{s=0}^{\infty} \beta^{s} U\left(c_{t+s}\left(\tilde{h}_{t+s}\right)\right)
$$

where the continuation history is defined by $\tilde{h}_{t}=\left(h_{t-1}, \pi_{t}\right)$, and then recursively by $\tilde{h}_{t+s+1}=\left(\tilde{h}_{t+s}, \pi_{t+s+1}\right)$. The continuation history is influenced by the government's decision, and the government takes that into account when maximizing (38). The household consumption function $c_{t}\left(h_{t}\right)$ is taken as given. 
Equilibrium. A sustainable equilibrium is a plan that satisfies the following conditions:

Definition 3. A sustainable equilibrium is a plan $(\Pi, X, P)$, such that, for every history $h_{t}$, and all $t$,

i. the household decisions $X$ solve the agent's problem (33) given $\Pi$ and $P$,

ii. prices $w, r$ satisfy (35),

iii. bonds $b$ solve the lender's problem (36),

iv. the government policy $\Pi$ solves the government problem (38).

If a plan constitutes a sustainable equilibrium, we will call it a sustainable plan. As usual, the key aspect of the sustainable equilibrium is that we require both the government and consumers to choose optimally after every history, not just the equilibrium history. Consumers act competitively, but the government does not, in that it knows that it choice today, $\pi_{t}=\Pi_{t}\left(h_{t}\right)$ affects both current prices $P_{t}\left(h_{t}\right)$, but also future prices. Note also that the government budget constraint is imposed in the government's problem only indirectly, in that the transfers in the agent's problem are a residual given by (34).

From plans to sequences. A deterministic sequence of policies, allocations and prices that is realized in the sequential equilibrium is called the outcome of the sequential equilibrium. Formally, take a sustainable equilibrium $(\Pi, X, P)$ and let $\left\{h_{t}^{*}\right\}$ be the realized history, given by $h_{0}^{*}=\varnothing$ and then recursively by $h_{t}^{*}=\left(h_{t-1}^{*}, \Pi_{t}\left(h_{t-1}^{*}\right)\right)$. Define $(\pi, x, p)$ by $\pi_{t}=\Pi_{t}\left(h_{t}^{*}\right), x_{t}=X_{t}\left(h_{t}^{*}\right)$, and $p_{t}=P_{t}\left(h_{t}^{*}\right)$. The sequence $(\pi, x, p)$ is the outcome of a sustainable equilibrium $(\Pi, X, P)$.

From sequences to plans. To proceed in the opposite direction, we will take an arbitrary sequence $(\pi, x, p)$, and define a revert-to-autarky plan $(\Pi, X, P)$. The revert-toautarky plan is equal to $(\pi, x, p)$ as long as a history given by $\pi$ is followed; otherwise, all actors revert to autarky.

Formally, we set $\Pi_{t}\left(h_{t-1}\right)=\pi_{t}, X_{t}\left(h_{t}\right)=x_{t}$, and $P_{t}\left(h_{t}\right)=p_{t}$, where the history $h_{t}$ is generated by $\pi, h_{t}=\left(\pi_{0}, \pi_{1}, \ldots, \pi_{t-1}\right)$. For any other history $h_{t}$, we assume that the country fully defaults $\left(\tau_{t}\left(h_{t}\right)=1\right)$ and imposes zero capital $\left(\tau_{t}^{K}\left(h_{t}\right)=0\right)$. The autarky 
allocation $X_{t}\left(h_{t}\right)$ consists of

$$
\begin{aligned}
c_{t}\left(h_{t}\right) & =g_{t}^{\text {aut }}\left(k_{t}\left(h_{t-1}\right)\right), \\
k_{t+1}\left(h_{t}\right) & =\frac{f\left(a_{t}, k_{t}\left(h_{t-1}\right)\right)+(1-\delta) k_{t}\left(h_{t-1}\right)-\phi\left(k_{t}\left(h_{t-1}\right), k_{t+1}\left(h_{t}\right)\right)-c_{t}\left(h_{t}\right)}{(1+\eta)(1+\gamma)} \\
b_{t+1}\left(h_{t}\right) & =0
\end{aligned}
$$

where $g_{t}^{\text {aut }}$ is the autarky consumption policy, as defined in the main text. The prices $w_{t}\left(h_{t}\right)$ and $r_{t}\left(h_{t}\right)$ are given by the standard first-order conditions (35). The bond price $R_{t}\left(h_{t}\right)$ is given by (37) which implies that $R_{t}\left(h_{t}\right)=\infty$, so as to keep $\left(1-\tau_{t}\left(h_{t-1}\right)\right) R_{t}\left(h_{t}\right)=$ $R_{t}^{*}$.

We will now show that the self-enforcing equilibrium can be rationalized as an outcome induced by a particular sustainable equilibrium: an equilibrium that is sustained by its associated revert-to-autarky plan.

Proposition 2. Given $\left\{R_{t}^{*}, a_{t}\right\}, b_{0}$ and $k_{0},(\pi, x, p)$, is a self-enforcing equilibrium if and only if it is an outcome of a sustainable equilibrium.

Proof. Suppose that $(\pi, x, p)$ is an outcome of a sustainable equilibrium. Then $x$ must solve the agent's problem (33) for $t=0$ and $h_{0}=\varnothing$. That is, condition $i$. of (2) holds. Conditions ii. and iii. of (2) hold by the construction of prices and by the definition of transfers in (34). Finally, suppose that condition iv. of (2) is violated. Then there is some period $t$ and some history $h_{t}$ such that

$$
\sum_{j=0}^{\infty} \hat{\beta}^{j} U\left(c_{t+j}\left(h_{t+j}\right)\right)<v_{t}^{\text {aut }}\left(k_{t}\left(h_{t-1}\right)\right),
$$

where $h_{t+j}=\left(h_{t+j-1}, \pi_{t+j}\right)$. But since $v_{t}^{\text {aut }}\left(k_{t}\left(h_{t-1}\right)\right)$ is the value of autarky, it can be achieved by a plan that reverts to autarky after history $h_{t-1}$. This implies that the realized history after $h_{t-1}$ differs from $h_{t}=\left(h_{t-1}, \pi_{t}\right)$, and so $(\pi, x, p)$ is not the outcome of the sustainable equilibrium, a contradiction.

Now suppose that $(\pi, x, p)$, is a self-enforcing equilibrium. We will show that the associated revert-to-autarky plan constitutes a sustainable equilibrium. Consider first histories with no deviations from $\pi$ before period $t$. Since $(\pi, x, p)$ is a competitive equilibrium, condition $i$. of (2) holds, and so $x$ solves (33). The government has a choice of whether to continue with its policy $\pi$, or whether to deviate. If it deviates in any 
way, the lender will never borrow from the country. Given that the lender is indifferent among all levels of $b$, it is optimal for the lender to do so. Given that the consumers cannot lend and it is not optimal to borrow since $R_{t}\left(h_{t}\right)=\infty$, consumers will choose consumption and capital levels consistent with autarky. Since no lending or borrowing takes place, it is optimal for the government to set the default rate to one. Given autarky and zero government consumption, it is optimal for the government to choose a zero tax on capital. Prices are consistent with those choices. By condition iv. of (2), the government then prefers to continue with its policy.

Consider now histories with a deviation from $\pi$ before $t$. It is again optimal for the lender to never borrow any amount from the country. Given that the price of debt is $R_{t}\left(h_{t}\right)=\infty$, it is not optimal for the consumers to borrow. Since there is no borrowing or lending, consumers will choose consumption and capital consistent with autarky, and it is optimal for the government to set the default rate equal to one. The capital tax rate is optimally set to zero since the government has no consumption to finance. Thus, the autarky plan is sustainable. 